\title{
PARTICIPATION IN MULTILATERAL TREATIES ${ }^{*}$
}

\section{Editorial introduction}

This section records the participation of Asian states in open, multilateral law-making treaties which mostly aim at world-wide adherence. The present Volume includes the cumulative and updated data contained in Volumes 1-5 of the Yearbook. For the purpose of this section states broadly situated west of Iran, north of Mongolia, east of Papua New Guinea and south of Indonesia will not be covered. The Editors wish to express their gratitude to all those international organizations which have so kindly responded to our request by making available information on the status of various categories of treaties.

Note:

- Where no other reference to specific sources is made, data are derived from Multilateral Treaties deposited with the Secretary-General - Status as at 31 December 1996 (ST/LEG/SER.E/15).

- No indication is given of reservations and declarations made.

- Sig. = signature; Cons. = consent to be bound.

\section{TABLE OF HEADINGS}

\section{Antarctica}

Commercial arbitration

Cultural matters

Cultural Property

Development matters

Dispute settlement

Environment, fauna and flora

Family matters

Finance

Health

Human rights, including rights of women and children

Humanitarian law in armed conflict

Intellectual property

International crimes

International representation

\author{
International trade \\ Judicial and administrative cooperation \\ Labour \\ Narcotic drugs \\ Nationality and statelessness \\ Nuclear material \\ Outer space \\ Privileges and immunities \\ Refugees \\ Road traffic and transport \\ Sea \\ Sea traffic and transport \\ Social matters \\ Telecommunications \\ Treaties \\ Weapons
}

* Compiled by Karin Arts, Assistant Editor.

Asian Yearbook of International Law, Volume 6 (Ko Swan Sik et al., eds.

๑ Kluwer Law International; printed in the Netherlands), pp. 233-283 


\section{ANTARCTICA}

Antarctic Treaty

Washington, 1 Dec. 1959

Entry into force: 23 June 1961

(Status as included in A/46/604 and TIF)

$\begin{array}{lllc}\text { State } & \text { Cons. } & \text { State } & \text { Cons. } \\ \text { China } & \text { yes } & \text { Korea (DPR) } & \text { yes } \\ \text { India } & \# & \text { Korea (Rep.) } & " \\ \text { Japan } & \# & \text { Papua New Guinea } & "\end{array}$

\section{COMMERCIAL ARBITRATION}

Convention on the Recognition and Enforcement of Foreign Arbitral Awards, 1958 New York, 1958

Entry into force: 7 June 1959

$\begin{array}{llllll}\text { State } & \text { Sig. } & \text { Cons. } & \text { State } & \text { Sig. } & \text { Cons. } \\ \text { Bangladesh } & \text { 6 May } 92 & & \text { Malaysia } & \text { 5 Nov 85 } & \\ \text { Cambodia } & \text { 5 Jan } 60 & & \text { Mongolia } & \text { 24 Oct } 94 & \\ \text { China } & \text { 22 Jan } 87 & & \text { Pakistan } & \text { 30 Dec 58 } & \\ \text { India } & \text { 10 Jun } 58 & \text { 13 Jul 60 } & \text { Philippines } & \text { 10 Jun 58 } & \text { 6 Jul 67 } \\ \text { Indonesia } & \text { 7 Oct } 81 & & \text { Singapore } & \text { 21 Aug } 86 & \\ \text { Japan } & \text { 20 Jun } 61 & & \text { Sri Lanka } & \text { 30 Dec 58 } & \text { 9 Apr 62 } \\ \text { Kazakhstan } & \text { 20 Nov 95 } & & \text { Thailand } & \text { 21 Dec 59 } & \\ \text { Korea (Rep.) } & \text { 8 Feb 73 } & & \text { Vietnam } & \text { 12 Sep 95 } & \end{array}$

\section{CULTURAL MATTERS}

Agreement for Facilitating the International Circulation of Visual and Auditory Materials of an Educational, Scientific and Cultural Character New York, 15 July 1949

Entry into force: 12 August 1954

$\begin{array}{llllll}\text { State } & \text { Sig. } & \text { Cons. } & \text { State } & \text { Sig. } & \text { Cons. } \\ \text { Afghanistan } & \text { 29 Dec 49 } & & \text { Pakistan } & & 16 \text { Feb 50 } \\ \text { Cambodia } & \text { 20 Feb 52 } & & \text { Philippines } & \text { 31 Dec 49 } & 13 \text { Nov 52 } \\ \text { Iran } & \text { 31 Dec 49 } & \text { 30 Dec 59 } & & & \end{array}$

Agreement on the Importation of Educational, Scientific and Cultural Materials

New York, 22 November 1950

Entry into force: 21 May 1952

$\begin{array}{llllll}\text { State } & \text { Sig. } & \text { Cons. } & \text { State } & \text { Sig. } & \text { Cons. } \\ \text { Afghanistan } & \text { 8 Oct 51 } & \text { 19 Mar 58 } & \text { Pakistan } & \text { 9 May 51 } & \text { 7 Jan 52 } \\ \text { Cambodia } & \text { 5 Nov 51 } & & \text { Philippines } & \text { 22 Nov 50 } & \text { 30 Aug 52 } \\ \text { Iran } & \text { 9 Feb 51 } & \text { 7 Jan 66 } & \text { Singapore } & & \text { 11 Jul 69 } \\ \text { Japan } & \text { 17 Jun 70 } & & \text { Sri Lanka } & & \text { 8 Jan 52 } \\ \text { Laos } & \text { 28 Feb 52 } & & \text { Thailand } & \text { 22 Nov 50 } & \text { 18 Jun 51 } \\ \text { Malaysia } & \text { 29 Jun 59 } & & & & \end{array}$


Convention concerning the International Exchange of Publications

Paris, 3 December 1958

Entry into force: 23 November 1961

(Status as at 18 April 1997, provided by UNESCO)

$\begin{array}{llll}\text { State } & \text { Cons. (deposit) } & \text { State } & \text { Cons. (deposit) } \\ \text { Brunei } & \text { 25 Jan 85 } & \text { Japan } & \text { 29 May } 84 \\ \text { Indonesia } & \text { 10 Jan 67 } & \text { Tajikistan } & \text { 28 Aug } 92\end{array}$

Convention concerning the Exchange of Official Publications and Government Documents between States

Paris, 3 December 1958

Entry into force: 30 May 1961

(Status as at 18 April 1997, provided by UNESCO)

$\begin{array}{llll}\text { State } & \text { Cons. (deposit) } & \text { State } & \text { Cons. (deposit) } \\ \text { Brunei } & 25 \text { Jan } 85 & \text { Sri Lanka } & 7 \text { Dec } 59 \\ \text { Indonesia } & 10 \text { Jan } 67 & \text { Tajikistan } & 28 \text { Aug } 92 \\ \text { Japan } & 29 \text { May } 84 & & \end{array}$

International Agreement for the Establishment of the University for Peace New York, UNGA Res. 35/55, 5 December 1980

Entry into force: 7 April 1981

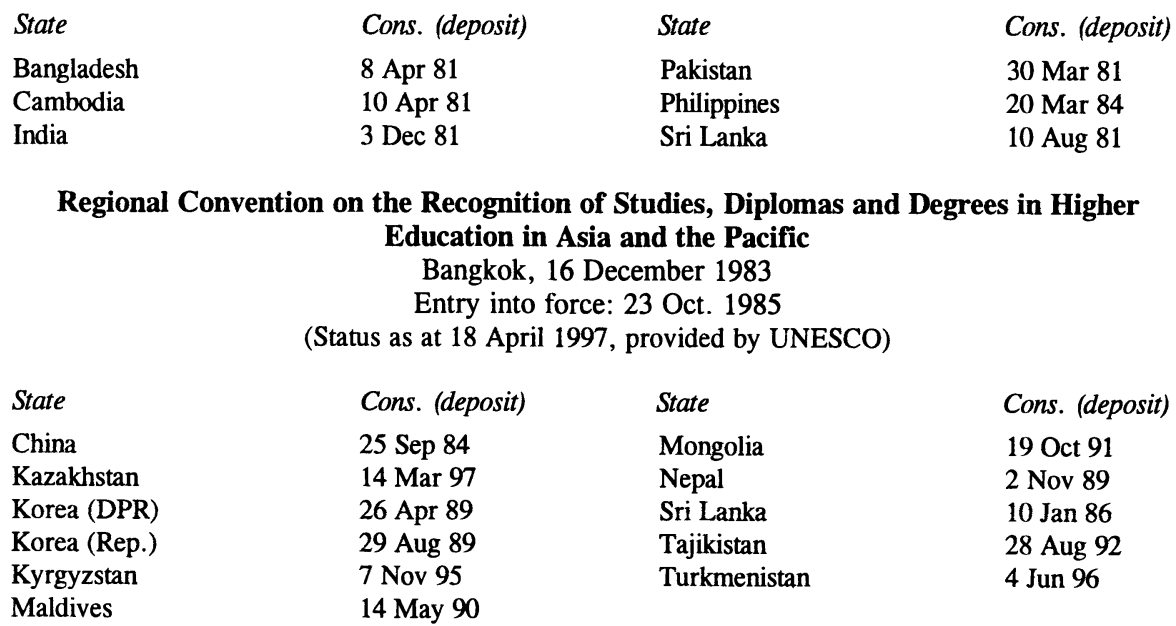

\section{CULTURAL PROPERTY}

Convention for the Protection of Cultural Property in the Event of Armed Conflict

The Hague, 14 May 1954

Entry into force: 7 August 1956

(Status as at 18 April 1997, provided by UNESCO) 


$\begin{array}{llll}\text { State } & \text { Cons. (deposit) } & \text { State } & \text { Cons. (deposit) } \\ \text { Cambodia } & \text { 4 Apr 62 } & \text { Mongolia } & \text { 4 Nov 61 } \\ \text { India } & \text { 16 Jun 58 } & \text { Myanmar } & \text { 10 Feb 56 } \\ \text { Indonesia } & \text { 10 Jan 67 } & \text { Pakistan } & \text { 27 Mar 59 } \\ \text { Iran } & \text { 22 Jun 59 } & \text { Tajikistan } & \text { 28 Aug 92 } \\ \text { Kazakhstan } & \text { 14 Mar 97 } & \text { Thailand } & \text { 2 May 58 } \\ \text { Kyrgyzstan } & \text { 3 Jul 95 } & \text { Uzbekistan } & \text { 21 Feb 96 } \\ \text { Malaysia } & \text { 12 Dec 60 } & & \end{array}$

\section{Protocol for the Protection of Cultural Property in the Event of Armed Conflict \\ The Hague, 14 May 1954}

Entry into force: 7 August 1956; for each state 3 months after date of deposit

(Status as at 18 April 1997, provided by UNESCO)

$\begin{array}{llll}\text { State } & \text { Cons. (deposit) } & \text { State } & \text { Cons. (deposit) } \\ \text { Cambodia } & \text { 4 Apr 62 } & \text { Myanmar } & 10 \text { Feb 56 } \\ \text { India } & \text { 16 Jun 58 } & \text { Pakistan } & \text { 27 Mar 59 } \\ \text { Indonesia } & \text { 26 Jul 67 } & \text { Tajikistan } & \text { 28 Aug } 92 \\ \text { Iran } & \text { 22 Jun 59 } & \text { Thailand } & \text { 2 May 58 } \\ \text { Kazakhstan } & \text { 14 Mar } 97 & \text { Uzbekistan } & \text { 21 Feb } 96 \\ \text { Malaysia } & 12 \text { Dec } 60 & & \end{array}$

Convention on the Means of Prohibiting and Preventing the Illicit Import, Export and Transfer of Ownership of Cultural Property, 1970

Paris, 14 November 1970

Entry into force: 24 April 1972; for each state 3 months after date of deposit

(Status as at 18 April 1997, provided by UNESCO)

$\begin{array}{llll}\text { State } & \text { Cons. (deposit) } & \text { State } & \text { Cons. (deposit) } \\ \text { Bangladesh } & 9 \text { Dec } 87 & \text { Kyrgyzstan } & \text { 3 Jul 95 } \\ \text { Cambodia } & 26 \text { Sep 72 } & \text { Mongolia } & \text { 23 May 91 } \\ \text { China } & \text { 28 Nov 89 } & \text { Nepal } & \text { 23 Jun 76 } \\ \text { India } & \text { 24 Jan 77 } & \text { Pakistan } & \text { 30 Apr 81 } \\ \text { Iran } & \text { 27 Jan 75 } & \text { Sri Lanka } & \text { 7 Apr 81 } \\ \text { Korea (DPR) } & \text { 13 May 83 } & \text { Tajikistan } & \text { 28 Aug 92 } \\ \text { Korea (Rep) } & \text { 14 Feb 83 } & \text { Uzbekistan } & \text { 15 Mar 96 }\end{array}$

Convention concerning the Protection of the World Cultural and Natural Heritage Paris, 16 November 1972

Entry into force: 17 December 1975

(Status as at 18 April 1997, provided by UNESCO) 


State
Afghanistan
Bangladesh
Cambodia
China
India
Indonesia
Iran
Japan
Korea (Rep.)
Kazakhstan
Kyrgyzstan
Laos
Malaysia

Cons. (deposit)
20 Mar 79
3 Aug 83
28 Nov 91
12 Dec 85
14 Nov 77
6 Jul 89
26 Feb 75
30 Jun 92
14 Sep 88
29 Apr 94
3 Jul 95
20 Mar 87
7 Dec 88

State

Maldives

Mongolia

Myanmar

Nepal

Pakistan

Philippines

Sri Lanka

Tajikistan

Thailand

Turkmenistan

Uzbekistan

Vietnam
Cons. (deposit)

22 May 86

2 Feb 90

29 Apr 94

20 Jun 78

23 Jul 76

19 Sep 85

6 Jun 80

28 Aug 92

17 Sep 87

30 Sep 94

13 Jan 93

19 Oct 87

\section{DEVELOPMENT MATTERS}

\section{Charter of the Asian and Pacific Development Centre ESCAP, Bangkok, 1 April 1982 \\ Entry into force: 1 July 1983}

\begin{tabular}{|c|c|c|c|c|c|}
\hline State & Sig. & Cons. & State & Sig. & Cons. \\
\hline Bangladesh & 9 Sep 82 & & Malaysia & & $9 \operatorname{Sep} 82$ \\
\hline Brunei & 14 Feb 85 & & Maldives & & 25 Apr 83 \\
\hline China & 18 Feb 83 & & Nepal & & 25 Apr 83 \\
\hline India & 25 Apr 83 & & Pakistan & & 9 Sep 82 \\
\hline Indonesia & 7 Jan 83 & & Philippines & & $15 \mathrm{Dec} 82$ \\
\hline Japan & 9 Sep 82 & & Sri Lanka & $9 \operatorname{Sep} 82$ & \\
\hline Korea (Rep.) & 9 Sep 82 & & Thailand & & 27 Jun 83 \\
\hline Laos & $9 \operatorname{Sep} 82$ & & Vietnam & & 9 Sep 82 \\
\hline Macau (ass. $\mathrm{n}$ & nber) & 3 Jun & & & \\
\hline
\end{tabular}

Agreement to Establish the South Centre

Geneva, 1 September 1994

Entry into force: 30 July 1995

$\begin{array}{llllll}\begin{array}{l}\text { State } \\ \text { Cambodia }\end{array} & \text { Sig. } & \text { Cons. } & \text { State } & \text { Sig. } & \begin{array}{c}\text { Cons. } \\ \text { China }\end{array} \\ \text { 30 Sep 94 } & & \text { Malaysia } & \text { 1 Dec 94 } & \text { 15 Jun 95 } \\ \text { India } & \text { 30 Sep 94 } & \text { 13 Dec 94 } & \text { Pakistan } & & \text { 12 May 95 } \\ \text { Indonesia } & \text { 30 Sep 94 } & \text { 17 Feb 95 } & \text { Sri Lanka } & \text { 30 Sep 94 } & \text { 16 Mar 95 } \\ \text { Iran } & \text { 30 Sep 94 } & & \text { Vietnam } & \text { 25 Nov 94 } & \text { 2 Jun 95 } \\ \text { Korea (DPR) } & \text { 6 Dec 94 } & \text { 31 May 95 } & & & \end{array}$




\section{DISPUTE SETTLEMENT}

\section{Convention on the Settlement of Investment Disputes between States and Nationals of Other States \\ Washington, 18 Mar 1965 \\ Entry into force: 14 October 1966 \\ (Status as at 3 June 1997, provided by the World Bank)}

\begin{tabular}{|c|c|c|c|c|c|}
\hline State & Sig. & Cons. & State & Sig. & Cons. \\
\hline Afghanistan & 30 Sep 66 & 25 Jun 68 & Nepal & 28 Sep 65 & 7 Jan 69 \\
\hline Bangladesh & 20 Nov 79 & 27 Mar 80 & Pakistan & 6 Jul 65 & $15 \operatorname{Sep} 66$ \\
\hline Cambodia & 5 Nov 93 & & Papua New & & \\
\hline China & 9 feb 90 & 7 Jan 93 & Guinea & 20 Oct 78 & 20 Oct 78 \\
\hline Indonesia & 16 Feb 68 & $28 \operatorname{Sep} 68$ & Philippines & 26 Sept 78 & 17 Nov 78 \\
\hline Japan & $23 \operatorname{Sep} 65$ & 17 Aug 67 & Singapore & 2 Feb 68 & 14 Oct 68 \\
\hline Korea (Rep.) & $18 \mathrm{Apr} 66$ & $21 \mathrm{Feb} 67$ & Sri Lanka & 30 Aug 67 & 12 Oct 67 \\
\hline Malaysia & 22 Oct 65 & 8 Aug 66 & Thailand & 6 Dec 85 & \\
\hline
\end{tabular}

Declarations recognizing as compulsory the jurisdiction of the International Court of Justice under Article 36, paragraph 2, of the Statute of the Court

$\begin{array}{llll}\text { State } & \text { Date of (last) deposit } & \text { State } & \text { Date of (last) deposit } \\ \text { Cambodia } & \text { 19 Sep 57 (with res.) } & \text { Pakistan } & \text { 13 Sep 60 (with res.) } \\ \text { India } & \text { 18 Sep 74 (with res.) } & \text { Philippines } & 18 \text { Jan 72 (with res.) } \\ \text { Japan } & \text { 15 Sep 58 (with res.) } & & \end{array}$

\section{ENVIRONMENT, FAUNA AND FLORA}

International Convention for the Prevention of Pollution of the Sea by Oil, as amended London, 12 May 1954

Entry into force: 26 July 1958; for each state 3 months after date of deposit

(Status as included in IMO doc. J/6233, as at 31 December 1995)

$\begin{array}{llll}\text { State } & \text { Cons. } & \text { State } & \text { Cons. } \\ \text { Bangladesh } & 28 \text { Sep } 81 & \text { Papua } & \\ \text { India } & 4 \text { Mar } 74 & \text { New Guinea } & 12 \text { Mar } 80 \\ \text { Japan } & 21 \text { Aug } 67 & \text { Philippines } & 19 \text { Nov } 63 \\ \text { Korea (Rep.) } & 31 \text { Jul 78 } & \text { Sri Lanka } & 30 \text { Aug } 83 \\ \text { Maldives } & 17 \text { May } 82 & & \end{array}$

International Convention Relating to Intervention on the High Seas in Cases of Oil Pollution Casualties

Brussels, 29 November 1969

Entry into force: 6 May 1975

(Status as included in IMO doc. J/6233, as at 31 December 1995)

$\begin{array}{llllll}\text { State } & \text { Cons. } & \text { E.i.f. } & \text { State } & \text { Cons. } & \text { E.i.f. } \\ \text { Bangladesh } & \text { 6 Nov 81 } & \text { 4 Feb 82 } & \text { Papua New } & & \\ \text { China } & \text { 23 Feb 90 } & \text { 24 May 90 } & \text { Guinea } & \text { 12 Mar 80 } & \text { 10 Jun 80 } \\ \text { Japan } & \text { 6 Apr 71 } & \text { 6 May 75 } & \text { Sri Lanka } & \text { 12 Apr 83 } & \text { 11 Jul 83 } \\ \text { Pakistan } & \text { 13 Jan 95 } & \text { 13 Apr 95 } & & & \end{array}$




\section{Protocol Relating to Intervention on the High Seas in Cases of Pollution by Substances Other Than Oil \\ London, 2 November 1973 \\ Entry into force: 30 March 1983}

(Status as included in IMO doc. J/6233, as at 31 December 1995)

$\begin{array}{lllllc}\text { State } & \text { Cons. } & \text { E.i.f. } & \text { State } & \text { Cons. } & \text { E.i.f. } \\ \text { China } & 23 \mathrm{Feb} 90 & \text { 24 May } 90 & \text { Pakistan } & 13 \text { Jan } 95 & 13 \text { Apr } 95\end{array}$

\section{International Convention on Civil Liability for Oil Pollution Damage}

Brussels, 29 November 1969

Entry into Force: 19 June 1975

(Status as included in IMO doc. J/6233, as at 31 December 1995)

$\begin{array}{llllll}\text { State } & \text { Cons. } & \text { E.i.f. } & \text { State } & \text { Cons. } & \text { E.i.f. } \\ \text { Brunei } & \text { 29 Sep 92 } & \text { 28 Dec 92 } & \text { Korea (Rep.) } & \text { 18 Dec 78 } & \text { 18 Mar 79 } \\ \text { Cambodia } & \text { 28 Nov 94 } & \text { 26 Feb 95 } & \text { Malaysia } & \text { 6 Jan 95 } & \text { 6 Apr 95 } \\ \text { China } & \text { 30 Jan 80 } & \text { 29 Apr 80 } & \text { Maldives } & \text { 16 Mar 81 } & \text { 14 Jun 81 } \\ \text { India } & \text { 1 May 87 } & \text { 30 Jul 87 } & \text { Papua New } & & \\ \text { Indonesia } & \text { 1 Sep 78 } & \text { 30 Nov 78 } & \text { Guinea } & \text { 12 Mar 80 } & \text { 10 Jun 80 } \\ \text { Japan } & \text { 3 Jun 76 } & \text { 1 Sep 76 } & \text { Singapore } & \text { 16 Sep 81 } & \text { 15 Dec 81 } \\ \text { Kazakhstan } & \text { 7 Mar 94 } & \text { 5 Jun 94 } & \text { Sri Lanka } & \text { 12 Apr 83 } & \text { 11 Jul 83 }\end{array}$

Protocol to the International Convention on Civil Liability for Oil Pollution Damage

London, 19 November 1976

Entry into force: 8 Apr 81

(Status as included in IMO doc. J/6233, as at 31 December 1995)

$\begin{array}{llllll}\text { State } & \text { Cons. } & \text { E.i.f. } & \text { State } & \text { Cons. } & \text { E.i.f. } \\ \text { Brunei } & \text { 29 Sep 92 } & \text { 28 Dec } 92 & \text { Korea (Rep.) } & \text { 8 Dec 92 } & \text { 8 Mar 93 } \\ \text { China } & \text { 29 Sep 86 } & \text { 28 Dec 86 } & \text { Maldives } & \text { 14 Jun 81 } & \text { 12 Sep 81 } \\ \text { India } & \text { 1 May 87 } & \text { 30 Jul 87 } & \text { Singapore } & \text { 15 Dec 81 } & \text { 15 Mar 82 } \\ \text { Japan } & \text { 24 Aug 94 } & \text { 22 Nov 94 } & & & \end{array}$

1992 Protocol to amend the International Convention on Civil Liability for

Oil Polution Damage, 1969

London, 27 November 1992

Entry into force: 30 May 1996

(Status as included in IMO doc. J/62333, as at 31 December 1995)

$\begin{array}{ll}\text { State } & \text { Cons. } \\ \text { Japan } & 24 \text { Aug } 94\end{array}$

Convention on Wetlands of International Importance especially as Waterfowl Habitat

Ramsar, 2 February 1971

Entry into force: 21 December 1975

(Status as provided by UNESCO on 18 April 1997) 


$\begin{array}{llll}\text { State } & \text { Cons. (deposit) } & \text { State } & \text { Cons. (deposit) } \\ \text { Bangladesh } & 21 \text { May } 92 & \text { Malaysia } & 10 \text { Nov } 94 \\ \text { China } & 31 \text { Mar } 92 & \text { Nepal } & 17 \text { Dec } 87 \\ \text { India } & 1 \text { Oct } 81 & \text { Pakistan } & 23 \text { Jul } 76 \\ \text { Indonesia } & 8 \text { Apr } 92 & \text { Papua New Guinea } & 16 \text { Mar } 93 \\ \text { Iran } & \text { 23 Jun } 75 & \text { Philippines } & 8 \text { Jul } 94 \\ \text { Japan } & 17 \text { Jun } 80 & \text { Sri Lanka } & 15 \text { Jun } 90 \\ \text { Korea (Rep.) } & 28 \text { Mar } 97 & \text { Vietnam } & \text { 20 Sep } 88\end{array}$

Protocol to amend the Convention on Wetlands of International Importance especially as Waterfowl Habitat

Paris, 3 December 1982

Entry into force: 1 October 1986

(Status as provided by UNESCO on 18 April 1997)

$\begin{array}{llll}\text { State } & \text { Cons. (deposit) } & \text { State } & \text { Cons. (deposit) } \\ \text { India } & 9 \text { Mar } 84 & \text { Japan } & \text { 26 Jun } 87 \\ \text { Iran } & 29 \text { Apr } 86 & \text { Pakistan } & 13 \text { Aug } 85\end{array}$

\section{Amendments to Articles 6 and 7 of the Convention on Wetlands of International Importance especially as Waterfowl Habitat Regina, 28 May 1987 \\ Entry into force: - \\ (Status as included in UNESCO Doc. CL 3343)}

$\begin{array}{llll}\text { State } & \text { Cons. (deposit) } & \text { State } & \text { Cons. (deposit) } \\ \text { Bangladesh } & 21 \text { May } 92 & \text { Japan } & 2 \text { Jun } 88 \\ \text { Indonesia } & 8 \text { Apr } 92 & \text { Pakistan } & 20 \text { Sep } 88 \\ \text { Iran } & 20 \text { Jul } 94 & & \end{array}$

International Convention on the Establishment of an International Fund for Compensation for Oil Pollution Damage

Brussels, 18 December 1971

Entry into force: 16 October 1978

(Status as included in IMO doc. J/6233, as at 31 December 1995)

$\begin{array}{llllll}\text { State } & \text { Cons. } & \text { E.i.f. } & \text { State } & \text { Cons. } & \text { E.i.f. } \\ \text { Brunei } & \text { 29 Sep 92 } & \text { 28 Dec 92 } & \text { Malaysia } & \text { 6 Jan 95 } & \text { 6 Apr 95 } \\ \text { India } & \text { 10 Jul 90 } & \text { 8 Oct 90 } & \text { Maldives } & \text { 16 Mar 81 } & \text { 14 Jun 81 } \\ \text { Indonesia } & \text { 1 Sep 78 } & \text { 30 Nov 78 } & \text { Papua New } & & \\ \text { Japan } & \text { 7 Jul 76 } & \text { 16 Oct 78 } & \text { Guinea } & \text { 12 Mar 80 } & \text { 10 Jun80 } \\ \text { Korea (Rep.) } & \text { 8 Dec 92 } & \text { 8 Mar 93 } & \text { Sri Lanka } & \text { 12 Apr 83 } & \text { 11 Jul 83 }\end{array}$

Convention on the Prevention of Marine Pollution by Dumping of Wastes and Other Matter, as amended

London, Mexico City, Moscow, Washington, 29 December 1972

Entry into force: 30 August 1975

(Status as included in IMO doc. J/6233, as at 31 December 1995)

$\begin{array}{llllll}\text { State } & \text { Cons. } & \text { E.i.f. } & \text { State } & \text { Cons. } & \text { E.i.f. } \\ \text { Afghanistan } & \text { 2 Apr 75 } & \text { 30 Aug 75 } & \text { Pakistan } & \text { 9 Mar 95 } & \text { 8 Apr 95 } \\ \text { China } & \text { 14 Nov 85 } & \text { 14 Dec 85 } & \text { Papua New } & & \\ \text { Japan } & 15 \text { Oct 80 } & \text { 14 Nov 80 } & \text { Guinea } & \text { 10 Mar 80 } & \text { 9 Apr 80 } \\ \text { Korea (Rep.) } & \text { 21 Dec 93 } & \text { 20 Jan 94 } & \text { Philippines } & \text { 10 Aug 73 } & \text { 30 Aug 75 }\end{array}$




\section{Protocol Relating to the International Convention for the Prevention of Pollution from Ships, as amended London, 17 February 1978 \\ Entry into force: 2 October 1983}

(Status as included in IMO doc. J/6233, as at 31 December 1995)

\begin{tabular}{|c|c|c|c|c|c|}
\hline State & Cons. & $\begin{array}{l}\text { Excepted } \\
\text { annexes }\end{array}$ & State & Cons. & $\begin{array}{l}\text { Excepted. } \\
\text { annexes. }\end{array}$ \\
\hline Brunei & 23 Oct 86 & III, IV, V & Korea (DPR) & 1 May 85 & \\
\hline Cambodia & 28 Nov 94 & & Korea (Rep.) & 23 Jul 84 & III, IV, V \\
\hline China & $1 \mathrm{Jul} 83$ & IV & Myanmar & 4 May 88 & III, IV, V \\
\hline Annex V: & 21 Nov 88 & & Pakistan & 22 Nov 94 & \\
\hline Annex III: & 13 Sept 94 & & Papua & & \\
\hline India & 24 Sep 86 & III, IV, V & New Guinea & 25 Oct 93 & \\
\hline Indonesia & 21 Oct 86 & III, IV, V & Singapore & 1 Nov 90 & IV, V \\
\hline Japan & 9 Jun 83 & & Annex III: & 2 Mar 94 & \\
\hline Kazakhstan & 7 Mar 94 & & Vietnam & 29 May 91 & III, IV, V \\
\hline
\end{tabular}

Convention for the Protection of the Ozone Layer, 1985 Vienna, 22 March 1985

Entry into force: 22 September 1988

State

Bangladesh

Brunei

China

India

Indonesia

Iran

Japan

Korea (DPR)

Korea (Rep.)

Malaysia

Maldives

Mongolia

Myanmar

Cons.
2 Aug 90
26 Jul 90
11 Sep 89
18 Mar 91
26 Jun 92
3 Oct 90
30 Sep 88
24 Jan 95
27 Feb 92
29 Aug 89
26 Apr 88
7 Mar 1996
24 Nov 93

State

Nepal

Pakistan

Papua

New Guinea

Philippines

Singapore

Sri Lanka

Tajikistan

Thailand

Turkmenistan

Uzbekistan

Vietnam

Cons.

$6 \mathrm{Jul} 94$

18 Dec 92

27 Oct 92

17 Jul 91

5 Jan 89

15 Dec 89

6 May 1996

7 Jul 89

18 Nov 93

18 May 93

26 Jan 94

Protocol on Substances that Deplete the Ozone Layer, 1987

Montreal, 16 September 1987

Entry into force: 1 January 1989

\begin{tabular}{|c|c|c|c|c|c|}
\hline State & Sig. & Cons. & State & Sig. & Cons. \\
\hline Bangladesh & & 2 Aug 90 & Myanmar & & 24 Nov 93 \\
\hline Brunei & & 27 May 93 & Nepal & & $6 \mathrm{Jul} 94$ \\
\hline China & & 14 Jun 91 & Pakistan & & $18 \operatorname{Dec} 92$ \\
\hline India & & 19 Jun 92 & Papua & & \\
\hline Indonesia & 21 Jul 88 & 26 Jun 92 & New Guinea & & 27 Oct 92 \\
\hline Iran & & 3 Oct 90 & Philippines & $14 \operatorname{Sep} 88$ & 17 Jul 91 \\
\hline Japan & $16 \operatorname{Sep} 87$ & 30 Sep 88 & Singapore & & 5 Jan 89 \\
\hline Korea (DPR) & & $24 \operatorname{Jan} 95$ & Sri Lanka & & 15 Dec 89 \\
\hline Korea (Rep.) & & 27 Feb 92 & Thailand & 15 Sep 88 & 7 Jul 89 \\
\hline Malaysia & & 29 Aug 89 & Turkmenistan & & 18 Nov 93 \\
\hline Maldives & 12 Jul 88 & 16 May 89 & Uzbekistan & & 18 May 93 \\
\hline Mongolia & & 7 Mar 96 & Vietnam & & $26 \mathrm{Jan} 94$ \\
\hline
\end{tabular}


Asian States operating under Article 5 paragraph 1 of the Montreal protocol: Bangladesh, China, Iran, Malaysia, Maldives, Philippines, Sri Lanka, Thailand.

\section{Amendment to the Montreal Protocol \\ London, 29 June 1990 \\ Entry into force: 10 August 1992}

State
Bangladesh
China
India
Indonesia
Japan
Korea (Rep.)
Malaysia
Maldives
Mongolia
Myanmar

Cons.

18 Mar 94

14 Jun 91

19 Jun 92

26 Jun 92

4 Sep 91

10 Dec 92

16 Jun 93

31 Jul 91

7 Mar 96

24 Nov 93
State

Nepal

Pakistan

Papua New Guinea

Philippines

Singapore

Sri Lanka

Thailand

Turkmenistan

Vietnam
Cons.

6 Jul 94

18 Dec 92

4 May 93

9 Aug 93

2 Mar 93

16 Jun 93

25 Jun 92

15 Mar 94

26 Jan 94

Amendment to the Montreal Protocol, 1992

Copenhagen, 25 November 1992

Entry into force: 14 June 1994

$\begin{array}{llll}\text { State } & \text { Cons. } & \text { State } & \text { Cons. } \\ \text { Japan } & 20 \text { Dec } 94 & \text { Pakistan } & 17 \text { Feb } 95 \\ \text { Korea (Rep.) } & 2 \text { Dec } 94 & \text { Tajikistan } & \text { 6 May 96 } \\ \text { Malaysia } & 5 \text { Aug } 93 & \text { Vietnam } & \text { 26 Jan 94 } \\ \text { Mongolia } & 7 \text { Mar } 96 & & \end{array}$

Convention on the Control of Transboundary Movements of Hazardous Wastes and Their Disposal, 1989

Basel, 22 March 1989

Entry into force: 5 May 1992

\begin{tabular}{|c|c|c|c|c|c|}
\hline State & Sig. & Cons. & State & Sig. & Cons. \\
\hline Afghanistan & 22 Mar 89 & & Nepal & & 15 Oct 96 \\
\hline Bangladesh & & 1 Apr 93 & Pakistan & & $26 \mathrm{Jul} 94$ \\
\hline China & $22 \operatorname{Mar} 90$ & 17 Dec 91 & Papua & & \\
\hline India & $15 \operatorname{Mar} 90$ & 24 Jun 92 & New Guinea & & 1 Sep 95 \\
\hline Indonesia & & 20 Sep 93 & Philippines & $22 \operatorname{Mar} 89$ & 21 Oct 93 \\
\hline Iran & & $5 \operatorname{Jan} 93$ & Singapore & & $2 \operatorname{Jan} 96$ \\
\hline Japan & & 17 Sep 93 & Sri Lanka & & 28 Aug 92 \\
\hline Korea (Rep.) & & $28 \mathrm{Feb} 94$ & Thailand & $22 \operatorname{Mar} 90$ & \\
\hline Kyrgyzstan & & 13 Aug 66 & Turkmenistan & & $25 \operatorname{Sep} 96$ \\
\hline Malaysia & & 8 Oct 93 & Uzbekistan & & 7 Feb 96 \\
\hline Maldives & & 28 Apr 92 & Vietnam & & $13 \mathrm{Mar} 95$ \\
\hline
\end{tabular}

Framework Convention on Climate Change, 1992

New York, 9 May 1992

Entry into force: 21 March 1994 


\begin{tabular}{|c|c|c|c|c|c|}
\hline State & Sig. & Cons. & State & Sig. & Cons. \\
\hline Afghanistan & 12 Jun 92 & & Maldives & 12 Jun 92 & 9 Nov 92 \\
\hline Bangladesh & 9 Jun 92 & 15 Apr 94 & Mongolia & 12 Jun 92 & 30 Sep 93 \\
\hline Bhutan & 11 Jun 92 & 25 Aug 95 & Myanmar & 11 Jun 92 & 25 Nov 94 \\
\hline Cambodia & & 18 Dec 95 & Nepal & 12 Jun 92 & 2 May 94 \\
\hline China & 11 Jun 92 & $5 \operatorname{Jan} 93$ & Pakistan & 13 Jun 92 & 1 Jun 94 \\
\hline India & 10 Jun 92 & 1 Nov 93 & Papua New & & \\
\hline Indonesia & 5 Jun 92 & 23 Aug 94 & Guinea & 13 Jun 92 & 6 Mar 93 \\
\hline Iran & 14 Jun 92 & $18 \mathrm{Jul} 96$ & Philippines & 12 Jun 92 & 2 Aug 94 \\
\hline Japan & 13 Jun 92 & 28 May 93 & Singapore & 13 Jun 92 & \\
\hline Kazakhstan & 8 Jun 92 & 17 May 95 & Sri Lanka & 10 Jun 92 & 23 Nov 93 \\
\hline Korea (DPR) & 11 Jun 92 & 5 Dec 94 & Thailand & 12 Jun 92 & $28 \operatorname{Dec} 94$ \\
\hline Korea (Rep.) & 13 Jun 92 & 14 Dec 93 & Turkmenistan & & 5 Jun 95 \\
\hline Laos & & 4 Jan 95 & Uzbekistan & & 20 Jun 93 \\
\hline Malaysia & 9 Jun 93 & 13 Jul 94 & Vietnam & 11 Jun 92 & 16 Nov 94 \\
\hline
\end{tabular}

\section{Convention on Biological Diversity, 1992}

Rio de Janeiro, 5 June 1992

Entry into force: 29 December 1993

\begin{tabular}{|c|c|c|c|c|c|}
\hline State & Sig. & Cons. & State & Sig. & Cons. \\
\hline Afghanistan & 12 Jun 92 & & Maldives & 12 Jun 92 & 9 Nov 92 \\
\hline Bangladesh & 5 Jun 92 & 3 May 94 & Mongolia & 12 Jun 92 & 30 Sep 93 \\
\hline Bhutan & 11 Jun 92 & 25 Aug 95 & Myanmar & 11 Jun 92 & 25 Nov 94 \\
\hline Cambodia & & 9 Feb 95 & Nepal & 12 Jun 92 & 23 Nov 93 \\
\hline China & 11 Jun 92 & $5 \operatorname{Jan} 93$ & Pakistan & 5 Jun 92 & $26 \mathrm{Jul} 94$ \\
\hline India & 5 Jun 92 & 18 Feb 94 & Papua New & & \\
\hline Indonesia & 5 Jun 92 & 23 Aug 94 & Guinea & 13 Jun 92 & 16 Mar 93 \\
\hline Iran & 14 Jun 92 & 6 Aug 96 & Philippines & 12 Jun 92 & 8 Oct 93 \\
\hline Japan & 13 Jun 92 & 28 May 93 & Singapore & 10 Mar 93 & 21 Dec 95 \\
\hline Kazakhstan & 9 Jun 92 & 6 Sep 94 & Sri Lanka & 10 Jun 92 & $23 \mathrm{Mar} 94$ \\
\hline Korea (DPR) & 11 Jun 92 & 26 Oct 94 & Thailand & 12 Jun 92 & \\
\hline Korea (Rep.) & 13 Jun 92 & 3 Oct 94 & Turkmenistan & & 18 Sep 96 \\
\hline Kyrgyzstan & & 6 Aug 96 & Uzbekistan & & $19 \mathrm{Jul} 95$ \\
\hline Laos & & $20 \operatorname{Sep} 96$ & Vietnam & 28 May 93 & 16 Nov 94 \\
\hline Malaysia & 12 Jun 92 & 24 Jun 94 & & & \\
\hline
\end{tabular}

\section{FAMILY MATTERS}

\section{Convention on the Recovery Abroad of Maintenance}

New York, 20 June 1956

Entry into force: 25 May 1957

$\begin{array}{llllll}\text { State } & \text { Sig. } & \text { Cons. } & \text { State } & \text { Sig. } & \text { Cons. } \\ \text { Cambodia } & \text { 20 Jun 56 } & & \text { Philippines } & \text { 20 Jun 56 } & \text { 21 Mar 68 } \\ \text { Pakistan } & & \text { 14 Jul 59 } & \text { Sri Lanka } & \text { 20 Jun 56 } & \text { 7 Aug 58 }\end{array}$

Convention on Consent to Marriage, Minimum Age for Marriage and

Registration of Marriages

New York, 10 December 1962

Entry into force: 9 December 1964 


\begin{tabular}{|c|c|c|c|c|}
\hline State & Sig. & Cons. & State & Sig. \\
\hline $\begin{array}{l}\text { Mongolia } \\
\text { Philipnines }\end{array}$ & 5 Feb 63 & $\begin{array}{l}6 \text { Jun } 91 \\
21 \operatorname{Jan} 65\end{array}$ & Sri Lanka & $12 \operatorname{Dec} 62$ \\
\hline
\end{tabular}

Convention on the Law Applicable to Maintenance Obligations Towards Children, The Hague, 24 October 1956

Entry into force: 1 January 1962

(Information provided by the Permanent Bureau of the Hague Conference on Private International Law on 14 October 1997)

$\begin{array}{lll}\text { State } & \text { Sig. } & \text { Cons. } \\ \text { Japan } & 10 \text { Feb 77 } & \text { 22 Jul 77 }\end{array}$

Convention on the Conflicts of Laws Relating to the Form of Testamentary Dispositions The Hague, 5 October 1961

Entry into force: 5 January 1964

(Information provided by the Permanent Bureau of the Hague Conference on Private International Law on 14 October 1997)

$\begin{array}{llllll}\text { State } & \text { Sig. } & \text { Cons. } & \text { State } & \text { Sig. } & \text { Cons. } \\ \text { Brunei } & & \text { 10 May 88 } & \text { Japan } & \text { 30 Jan 64 } & \text { 3 Jun 64 }\end{array}$

Convention on the Law Applicable to Maintenance Obligations

The Hague, 2 October 1973

Entry into force: 1 October 1977

(Information provided by the Permanent Bureau of the

Hague Conference on Private International Law on 14 October 1997)

$\begin{array}{lll}\text { State } & \text { Sig. } & \text { Cons. } \\ \text { Japan } & 28 \text { Feb } 86 & \text { 5 Jun } 86\end{array}$

Convention on Protection of Children and Co-operation in respect of Intercountry Adoption

The Hague, 29 May 1993

Entry into force: 1 May 1995

(Status on 4 June 1997 as furnished by the Permanent Bureau of the Hague Conference on Private International Law)

$\begin{array}{llllll}\text { State } & \text { Sig. } & \text { Cons. } & \text { State } & \text { Sig. } & \text { Cons. } \\ \text { Sri Lanka } & \text { 24 May 94 } & \text { 23 Jan 95 } & \text { Philippines } & \text { 17 Jul 95 } & \text { 2 Jul 96 }\end{array}$

\section{FINANCE}

Agreement Establishing the Asian Development Bank

Manila, 4 December 1965

Entry into force: 22 August 1966 


\begin{tabular}{|c|c|c|c|c|c|}
\hline State & Sig. & Cons. & State & Sig. & Cons. \\
\hline Afghanistan & 4 Dec 65 & 22 Aug 66 & Maldives & & $14 \mathrm{Feb} 78$ \\
\hline Bangladesh & & 14 Mar 73 & Myanmar & & $26 \mathrm{Apr} 73$ \\
\hline Bhutan & & 15 Apr 82 & Nepal & $4 \operatorname{Dec} 65$ & 21 Jun 66 \\
\hline Cambodia & 4 Dec 65 & 30 Sep 66 & Pakistan & 4 Dec 65 & 12 May 66 \\
\hline China & 10 Mar 86 & & Papua & & \\
\hline Hong Kong & 27 Mar 69 & & New Guinea & & 8 Apr 71 \\
\hline India & 4 Dec 65 & $20 \mathrm{Jul} 66$ & Philippines & $4 \operatorname{Dec} 65$ & $5 \mathrm{Jul} 66$ \\
\hline Indonesia & 24 Nov 66 & & Singapore & 28 Jan 66 & 21 Sep 66 \\
\hline Iran & 4 Dec 65 & & Sri Lanka & 4 Dec 65 & $29 \operatorname{Sep} 66$ \\
\hline Japan & $4 \operatorname{Dec} 65$ & 16 Aug 66 & Taipei, China & $4 \operatorname{Dec} 65$ & $22 \operatorname{Sep} 66$ \\
\hline Korea (Rep.) & 4 Dec 65 & 16 Aug 66 & Thailand & $4 \operatorname{Dec} 65$ & 16 Aug 66 \\
\hline Laos & 4 Dec 65 & 30 Aug 66 & Vietnam & 28 Jan 66 & $22 \operatorname{Sep} 66$ \\
\hline Malaysia & 4 Dec 65 & 16 Aug 66 & & & \\
\hline
\end{tabular}

Convention Establishing the Multilateral Investment Guarantee Agency, 1988 Seoul, 11 October 1985

Entry into force: 12 April 1988

(Status as at 3 June 1997, provided by the World Bank)

$\begin{array}{llllll}\text { State } & \text { Sig. } & \text { Cons. (deposit) } & \text { State } & \text { Sig. } & \text { Cons. (deposit) } \\ \text { Bangladesh } & \text { 13 Mar 87 } & \text { 13 Mar 87 } & \text { Nepal } & \text { 23 Sep 92 } & \text { 23 Sep 93 } \\ \text { Cambodia } & \text { 1 Oct 93 } & & \text { Pakistan } & \text { 7 Jul 86 } & \text { 1 Dec 86 } \\ \text { China } & \text { 23 Apr 88 } & \text { 30 Apr 88 } & \text { Papua New } & & \\ \text { India } & \text { 13 Apr 92 } & \text { 20 Sep 93 } & \text { Guinea } & \text { 9 May 90 } & \text { 29 Oct 90 } \\ \text { Indonesia } & \text { 26 Jun 86 } & \text { 26 Sep 86 } & \text { Philippines } & \text { 15 Sep 86 } & \text { 22 Nov 93 } \\ \text { Japan } & \text { 12 Sep 86 } & \text { 5 Jun 87 } & \text { Sri Lanka } & \text { 3 Oct 86 } & \text { 27 May 88 } \\ \text { Korea (Rep.) } & \text { 11 Oct 85 } & \text { 24 Nov 87 } & \text { Vietnam } & \text { 27 Sep 93 } & \text { 4 Apr 94 } \\ \text { Malaysia } & \text { 2 Jul 91 } & \text { 2 Aug 91 } & & & \end{array}$

\section{HEALTH}

Protocol Concerning the Office International d'Hygiène Publique

New York, 22 July 1946

Entry into force: 20 October 1947

$\begin{array}{llllll}\text { State } & \text { Sig. } & \text { Cons. } & \text { State } & \text { Sig. } & \text { Cons. } \\ \text { Afghanistan } & & \text { 19 Apr 48 } & \text { Myanmar } & & \text { 1 Jul } 48 \\ \begin{array}{l}\text { China } \\ \text { India }\end{array} & & \text { 22 Jul 46 } & \text { Pakistan } & & \text { 23 Jun 48 } \\ \text { Iran } & \text { 22 Jul 46 } & \text { 12 Jan 48 } & \text { Philippines } & \text { 22 Jul 46 } \\ \text { Japan } & \text { 22 Jul 46 } & \text { 27 Jan 47 } & \text { Sri Lanka } & \text { 23 May 49 } \\ & & \text { 11 Dec 51 } & \text { Thailand } & \text { 22 Jul 46 }\end{array}$

HUMAN RIGHTS, INCLUDING RIGHTS OF WOMEN AND CHILDREN

Convention on the Political Rights of Women

New York, 31 March 1953

Entry into force: 7 July 1954 


$\begin{array}{llllll}\text { State } & \text { Sig. } & \text { Cons. } & \text { State } & \text { Sig. } & \text { Cons. } \\ \text { Afghanistan } & \text { 16 Nov 66 } & & \text { Myanmar } & \text { 14 Sep 54 } & \\ \text { India } & \text { 29 Apr 53 } & \text { 1 Nov 61 } & \text { Nepal } & \text { 26 Apr 66 } & \\ \text { Indonesia } & \text { 31 Mar 53 } & \text { 16 Dec 58 } & \text { Pakistan } & \text { 18 May 54 } & \text { 7 Dec 54 } \\ \text { Japan } & \text { 1 Apr 55 } & \text { 13 Jul 55 } & \text { Papua } & & \\ \text { Korea (Rep.) } & \text { 23 Jun 59 } & & \text { New Guinea } & & \text { 27 Jan 82 } \\ \text { Laos } & \text { 28 Jan 69 } & & \text { Philippines } & \text { 23 Sep 53 } & \text { 12 Sep 57 } \\ \text { Mongolia } & \text { 18 Aug 65 } & & \text { Thailand } & \text { 5 Mar 54 } & \text { 30 Nov 54 }\end{array}$

Convention on the Nationality of Married Women New York, 20 February 1957

Entry into force: 11 August 1958

$\begin{array}{llllll}\text { State } & \text { Sig. } & \text { Cons. } & \text { State } & \text { Sig. } & \text { Cons. } \\ \text { India } & \text { 15 May 57 } & & \text { Singapore } & & 18 \text { Mar 66 } \\ \begin{array}{l}\text { Malaysia } \\ \text { Pakistan }\end{array} & & \text { 24 Feb 59 } & \text { Sri Lanka } & & 30 \text { May 58 }\end{array}$

Convention against Discrimination in Education, 1960

Paris, 14 December 1960

Entry into force: 22 May 1962

(Status as provided by UNESCO on 18 April 1997)

$\begin{array}{lclc}\text { State } & \text { Cons. (deposit) } & \text { State } & \text { Cons. (deposit) } \\ \text { Brunei } & 25 \text { Jan } 85 & \text { Mongolia } & 4 \text { Nov } 64 \\ \text { Indonesia } & \text { 10 Jan 67 } & \text { Philippines } & 19 \text { Nov } 64 \\ \text { Iran } & 17 \text { Jul } 68 & \text { Sri Lanka } & 11 \text { Aug } 63 \\ \text { Kyrgyzstan } & \text { 3 Jul } 95 & \text { Tajikistan } & 28 \text { Aug } 92\end{array}$

International Covenant on Economic, Social and Cultural Rights, 1966

New York, 16 December 1966

Entry into force: 3 January 1976

$\begin{array}{llllll}\text { State } & \text { Sig. } & \text { Cons. } & \text { State } & \text { Sig. } & \text { Cons. } \\ \begin{array}{l}\text { Afghanistan } \\ \text { Cambodia }\end{array} & & \text { 24 Jan 83 } & \text { Kyrgyzstan } & & \text { 7 Oct } 94 \\ \text { India } & & \text { 26 May 92 } & \text { Mongolia } & \text { 5 Jun 68 } & \text { 18 Nov 74 } \\ \text { Iran } & \text { 4 Apr 68 } & \text { 10 Apr 79 } & \text { Nepal } & & \text { 14 May 91 } \\ \text { Japan } & \text { 24 Ju May 78 } & \text { 21 Jun 79 } & \text { Philippines } & \text { 19 Dec 66 } & \text { 7 Jun 74 } \\ \text { Korea (DPR) } & & \text { Sri Lanka } & & \text { 11 Jun 80 } \\ \text { Korea (Rep.) } & & \text { 10 Apr 90 } & \text { Uzbekistan } & & \text { 28 Sep 95 } \\ & & \text { Vietnam } & & \text { 24 Sep 82 }\end{array}$

\section{International Covenant on Civil and Political Rights, 1966}

New York, 16 December 1966

Entry into force: 23 March 1976

\begin{tabular}{llllll} 
State & Sign. & Cons. & State & Sign. & Cons. \\
Afghanistan & & 24 Jan 83 & Kyrgyzstan & & 7 Oct 94 \\
Cambodia & \multirow{2}{*}{17 Oct 80} & 26 May 92 & Nepal & & 14 May 91 \\
India & & 10 Apr 79 & Philippines & 19 Dec 66 & 23 Oct 86 \\
Iran & 30 May 78 & 21 Jun 79 & Sri Lanka & & 11 Jun 80 \\
Japan & 30 May 78 & 21 Jun 79 & Thailand & & 29 Oct 96 \\
Korea (DPR) & & 14 Sep 81 & Uzbekistan & & 28 Sep 95 \\
Korea (Rep.) & & 10 Apr 90 & Vietnam & & 24 Sep 82
\end{tabular}


Optional Protocol to the International Covenant on Civil and Political Rights, 1966 New York, 16 December 1966

Entry into force: 23 March 1976

$\begin{array}{lllllc}\text { State } & \text { Sig. } & \text { Cons. } & \text { State } & \text { Sig. } & \text { Cons. } \\ \text { Korea (Rep.) } & & 10 \text { Apr } 90 & \text { Nepal } & & 14 \text { May } 91 \\ \text { Kyrgyzstan } & 7 \text { Oct } 94 & \text { Philippines } & \text { 19 Dec 66 } & \text { 22 Aug 89 } \\ \text { Mongolia } & 16 \text { Apr } 91 & \text { Uzbekistan } & & \text { 28 Sep 95 }\end{array}$

International Convention on the Elimination of All Forms of Racial Discrimination, 1966 New York, 7 March 1966

Entry into force: 4 January 1969

\begin{tabular}{|c|c|c|c|c|c|}
\hline State & Sig. & Cons. & State & Sig. & Cons \\
\hline Afghanistan & & $6 \mathrm{Jul} 83$ & Mongolia & 3 May 66 & 6 Aug 69 \\
\hline Bangladesh & & 11 Jun 79 & Nepal & & $30 \operatorname{Jan} 71$ \\
\hline Bhutan & 26 Mar 73 & & Pakistan & 19 Sep 66 & $21 \operatorname{Sep} 66$ \\
\hline Cambodia & 12 Apr 66 & 28 Nov 83 & Papua Nev & & \\
\hline China & & $29 \operatorname{Dec} 81$ & $27 \mathrm{Jan} 82$ & & \\
\hline India & 2 Mar 67 & $3 \operatorname{Dec} 68$ & Philippines & 7 Mar 66 & 15 Sep 67 \\
\hline Iran & 8 Mar 67 & 19 Aug 68 & Sri Lanka & & $18 \mathrm{Feb} 82$ \\
\hline Japan & & 15 Dec 95 & Tajikistan & & 11 Jan 95 \\
\hline Korea (Rep.) & 8 Aug 78 & $5 \operatorname{Dec} 78$ & Turkmenis & & 29 Sep 94 \\
\hline Laos & & $22 \mathrm{Feb} 74$ & Uzbekistan & & 28 Sep 95 \\
\hline Maldives & & 24 Apr 84 & Vietnam & & 9 Jun 82 \\
\hline
\end{tabular}

Amendment to article 8 of the International Convention on the Elimination of All Forms of Racial Discrimination

14th Meeting of the states parties, 15 January 1992

Entered into force: -

$\begin{array}{ll}\text { State } & \text { Acceptance } \\ \text { Korea (Rep.) } & 30 \text { Nov } 93\end{array}$

Convention on the Elimination of All Forms of Discrimination against Women New York, 18 December 1979

Entry into force: 3 September 1981

\begin{tabular}{|c|c|c|c|c|c|}
\hline State & Sig. & Cons. & State & Sig. & Cons. \\
\hline Afghanistan & 14 Aug 80 & & Mongolia & 17 Jul 80 & $20 \mathrm{Jul} 81$ \\
\hline Bangladesh & & 6 Nov 84 & Nepal & 5 Feb 91 & 22 Apr 91 \\
\hline Bhutan & 17 Jul 80 & 31 Aug 81 & Papua & & \\
\hline Cambodia & 17 Oct 80 & 15 Oct 92 & New Guinea & $12 \operatorname{Jan} 95$ & \\
\hline China & 17 Jul 80 & 4 Nov 80 & Philippines & $15 \mathrm{Jul} 80$ & 5 Aug 81 \\
\hline India & 30 Jul 80 & 9 Jul 93 & Singapore & & 5 Oct 95 \\
\hline Indonesia & 29 Jul 80 & 13 Sep 84 & Sri Lanka & 17 Jul 80 & 5 Oct 81 \\
\hline Japan & 17 Jul 80 & 25 Jun 85 & Tajikistan & & 26 Oct 93 \\
\hline Korea (Rep.) & 25 May 83 & 27 Dec 84 & Thailand & & 9 Aug 85 \\
\hline Laos & 17 Jul 80 & 14 Aug 81 & Uzbekistan & & 19 Jul 95 \\
\hline Malaysia & 5 Jun 95 & & Vietnam & 29 Jul 80 & 17 Feb 82 \\
\hline Maldives & $1 \mathrm{Jul} 93$ & & & & \\
\hline
\end{tabular}




\section{Convention against Torture and Other Cruel, Inhuman or Degrading Treatment or Punishment \\ New York, 10 December 1984 \\ Entry into force: 26 June 1987}

$\begin{array}{llllll}\text { State } & \text { Sig. } & \text { Cons. } & \text { State } & \text { Sig. } & \text { Cons. } \\ \text { Afghanistan } & 4 \text { Feb } 85 & \text { 1 Apr } 87 & \text { Philippines } & & \text { 18 Jun } 86 \\ \text { Cambodia } & & 15 \text { Oct } 92 & \text { Seychelles } & & \text { 5 May } 92 \\ \text { China } & \text { 12 Dec 86 } & \text { 4 Oct } 88 & \text { Sri Lanka } & & \text { 3 Jan } 94 \\ \text { Indonesia } & 23 \text { Oct } 85 & & \text { Tajikistan } & & \text { 11 Jan } 95 \\ \text { Korea (Rep.) } & & \text { 9 Jan 95 } & \text { Uzbekistan } & & \text { 28 Sep 95 } \\ \text { Nepal } & & \text { 14 May 91 } & & \end{array}$

International Convention against Apartheid in Sports, 1985

New York, 10 December 1985

Entry into force: 3 April 1988

$\begin{array}{llllll}\text { State } & \text { Sig. } & \text { Cons. } & \text { State } & \text { Sig. } & \text { Cons. } \\ \text { China } & \text { 21 Oct 87 } & & \text { Maldives } & \text { 3 Oct 86 } & \\ \text { India } & & \text { 12 Sep 90 } & \text { Mongolia } & \text { 16 May 86 } & \text { 16 Dec 87 } \\ \text { Indonesia } & \text { 16 May 86 } & \text { 23 Jul 93 } & \text { Nepal } & \text { 24 Jun 86 } & \text { 1 Mar 89 } \\ \text { Iran } & \text { 16 May 86 } & \text { 12 Jan 88 } & \text { Philippines } & \text { 16 May 86 } & \text { 27 Jul 87 } \\ \text { Malaysia } & \text { 16 May 86 } & & & & \end{array}$

Convention on the Rights of the Child, 1989

New York, 20 November 1989

Entry into force: 2 September 1990

\begin{tabular}{|c|c|c|c|c|c|}
\hline State & Sig. & Cons. & State & Sig. & Cons. \\
\hline Afghanistan & 27 Sep 90 & 28 Mar 94 & & & \\
\hline Bangladesh & 26 Jan 90 & 3 Aug 90 & Maldives & 21 Aug 90 & $11 \mathrm{Feb} 91$ \\
\hline Bhutan & 4 Jun 90 & 1 Aug 90 & Mongolia & $26 \mathrm{Jan} 90$ & 5 Jul 90 \\
\hline Brunei & & 27 Dec 95 & Myanmar & & $15 \mathrm{Jul} 91$ \\
\hline Cambodia & & 15 Oct 92 & Nepal & $26 \mathrm{Jan} 90$ & $14 \operatorname{Sep} 90$ \\
\hline China & 29 Aug 90 & $2 \operatorname{Mar} 92$ & Pakistan & $20 \operatorname{Sep} 90$ & 12 Nov 90 \\
\hline India & & $11 \operatorname{Dec} 92$ & Papua New & & \\
\hline Indonesia & $26 \operatorname{Jan} 90$ & 5 Sep 90 & Guinea & 30 Sep 90 & 2 Mar 93 \\
\hline Iran & 5 Sep 91 & 13 Jul 94 & Philippines & $26 \operatorname{Jan} 90$ & 21 Aug 90 \\
\hline Japan & 21 Sep 90 & 22 Apr 94 & Singapore & & 5 Oct 95 \\
\hline Kazakhstan & $16 \mathrm{Feb} 94$ & 12 Aug 94 & Sri Lanka & $26 \operatorname{Jan} 90$ & $12 \mathrm{Jul} 91$ \\
\hline Korea (DPR) & 23 Aug 90 & $21 \operatorname{Sep} 90$ & Tajikistan & 26 Oct 93 & \\
\hline Korea (Rep.) & $25 \operatorname{Sep} 90$ & 20 Nov 91 & Thailand & 27 Mar 92 & \\
\hline Kyrgyzstan & & 7 Oct 94 & Turkmenistan & 20 Sep 93 & \\
\hline Laos & & 8 May 91 & Uzbekistan & & 29 Jun 94 \\
\hline Malaysia & & 17 Feb 95 & Vietnam & $26 \operatorname{Jan} 90$ & $28 \mathrm{Feb} 90$ \\
\hline
\end{tabular}


International Convention on the Protection of the Rights of All Migrant Workers and Members of Their Families

UNGA, New York, 18 December 1990

Entry into force: -

$\begin{array}{lllll}\text { State } & \text { Sig. } & \text { Cons. } & \text { State } & \text { Cons. } \\ \text { Philippines } & 15 \text { Nov } 93 & 5 \text { Jul } 95 & \text { Sri Lanka } & 11 \text { Mar } 96\end{array}$

\section{HUMANITARIAN LAW IN ARMED CONFLICT}

International Conventions for the Protection of Victims of War, I-IV

Geneva, 12 August 1949

Entry into force: 21 October 1950

(Status as provided by the ICRC on 6 June 1997)

\begin{tabular}{|c|c|c|c|}
\hline State & Cons. & State & Cons. \\
\hline Afghanistan & $26 \operatorname{Sep} 56$ & Maldives & 18 Jun 91 \\
\hline Bangladesh & 4 Apr 72 & Mongolia & $20 \mathrm{Dec} 58$ \\
\hline Bhutan & 10 Jan 91 & Myanmar & 25 Aug 92 \\
\hline Brunei & 14 Oct 91 & Nepal & 7 Feb 64 \\
\hline Cambodia & 8 Dec 58 & Pakistan & 12 Jun 51 \\
\hline China & 28 Dec 56 & Papua & \\
\hline India & 9 Nov 50 & New Guinea & 26 May 76 \\
\hline Indonesia & 30 Sep 58 & Philippines & 6 Oct 52 \\
\hline Iran & 20 Feb 57 & Seychelles & 8 Nov 84 \\
\hline Japan & 21 Apr 53 & Singapore & 27 Apr 73 \\
\hline Kazakhstan & 5 May 92 & Sri Lanka & 28 Feb 59 \\
\hline Korea (DPR) & 27 Aug 57 & Tajikistan & $13 \operatorname{Jan} 93$ \\
\hline Korea (Rep.) & 16 Aug 66 & Thailand & $29 \operatorname{Dec} 54$ \\
\hline Kyrgyzstan & 18 Sep 92 & Turkmenistan & 10 Apr 92 \\
\hline Laos & 29 Oct 56 & Uzbekistan & 8 Oct 93 \\
\hline Malaysia & 24 Aug 62 & Vietnam & 28 Jun 57 \\
\hline
\end{tabular}

Protocol I Additional to the Geneva Conventions of 12 August 1949, and Relating to the Protection of Victims of International Armed Conflicts, 1977

Geneva, 10 June 1977

Entry into force: 7 December 1978

(Status as provided by the ICRC on 6 June 1997)

$\begin{array}{llll}\text { State } & \text { Cons. } & \text { State } & \text { Cons. } \\ \text { Bangladesh } & 8 \text { Sep } 80 & \text { Maldives } & \text { 3 Sep } 91 \\ \text { Brunei } & 14 \text { Oct } 91 & \text { Mongolia } & \text { Dec } 95 \\ \text { China } & 14 \text { Sep } 83 & \text { Tajikistan } & 13 \text { Jan } 93 \\ \text { Kazakhstan } & 5 \text { May } 92 & \text { Turkmenistan } & 10 \text { Apr } 92 \\ \text { Korea (DPR) } & 9 \text { Mar } 88 & \text { Uzbekistan } & 8 \text { Oct } 93 \\ \text { Korea (Rep.) } & 15 \text { Jan } 82 & \text { Vietnam } & 19 \text { Oct } 81 \\ \text { Kyrgyzstan } & 18 \text { Sep } 92 & & \end{array}$




\section{Protocol II Additional to the Geneva Conventions of 12 August 1949, and Relating to the Protection of Victims of Non-International Armed Conflicts, 1977} Geneva, 10 June 1977

Entry into force: 7 December 1978

(Status as provided by the ICRC on 6 June 1997)

State
Bangladesh
Brunei
China
Kazakhstan
Korea (Rep.)
Kyrgyzstan
Laos

Cons.

8 Sep 80

14 Oct 91

$14 \operatorname{Sep} 83$

5 May 92

15 Jan 82

18 Sep 92

18 Nov 80
State

Maldives

Mongolia

Philippines

Tajikistan

Turkmenistan

Uzbekistan
Cons.

3 Sep 91

6 Dec 95

11 Dec 86

13 Jan 93

10 Apr 92

8 Oct 93

\section{INTELLECTUAL PROPERTY}

\section{Convention for the Protection of Industrial Property}

Paris, 1883, most recently revised Stockholm, 1967 and amended 1979

(Status as included in WIPO doc. 423(E) of 3 July 1997)

\begin{tabular}{|c|c|c|c|c|c|}
\hline State & Party & $\begin{array}{l}\text { Latest Act } \\
\text { to which } \\
\text { State is party }\end{array}$ & State & Party & $\begin{array}{l}\text { Latest Act to } \\
\text { which State } \\
\text { is party }\end{array}$ \\
\hline Bangladesh & 3 Mar 91 & Stockholm & Mongolia & 21 Apr 85 & Stockholm \\
\hline China & 19 Mar 85 & id. & Philippines & 27 Sep 65 & Lisbon, \\
\hline Indonesia & $24 \operatorname{Dec} 50$ & id. & & & Stockholm \\
\hline Iran & 16 Dec 59 & Lisbon & Singapore & 23 Feb 95 & Stockholm \\
\hline Japan & 15 Jul 1899 & Stockholm & Sri Lanka & $29 \operatorname{Dec} 52$ & London, \\
\hline Kazakhstan & 25 Dec 91 & id. & & & Stockholm \\
\hline Korea (DPR) & 10 Jun 80 & id. & Tajikistan & $25 \operatorname{Dec} 91$ & Stockholm \\
\hline Korea (Rep.) & 4 May 80 & id. & Turkmenistan & $25 \operatorname{Dec} 91$ & id. \\
\hline Kyrgyzstan & $25 \operatorname{Dec} 91$ & id. & Uzbekistan & $25 \operatorname{Dec} 91$ & id. \\
\hline Malaysia & 1 Jan 89 & id. & Vietnam & 8 Mar 49 & id. \\
\hline
\end{tabular}

Convention for the Protection of Literacy and Artistic Works

Berne, 1886, most recently revised Paris, 1971 and amended 1979 (Status as included in WIPO doc. 423(E) of 3 July 1997)

\begin{tabular}{|c|c|c|c|c|c|}
\hline State & Party & $\begin{array}{l}\text { Latest Act to } \\
\text { which State } \\
\text { is party }\end{array}$ & State & Party & $\begin{array}{l}\text { Latest Act to } \\
\text { which State } \\
\text { is party }\end{array}$ \\
\hline $\begin{array}{l}\text { China } \\
\text { India }\end{array}$ & $\begin{array}{l}15 \text { Oct } 92 \\
1 \text { Apr } 28\end{array}$ & $\begin{array}{l}\text { Paris } \\
\text { id. }\end{array}$ & Pakistan & $5 \mathrm{Jul} 48$ & $\begin{array}{l}\text { Rome, } \\
\text { Stockholm }\end{array}$ \\
\hline Indonesia & $5 \operatorname{Sep} 97$ & Paris & Philippines & 1 Aug 51 & Paris \\
\hline Japan & 15 Jul 1899 & id. & Sri Lanka & 20 Jul 59 & Rome, Paris \\
\hline Korea (Rep.) & 21 Aug 96 & id. & Thailand & $17 \mathrm{Jul} 31$ & Paris \\
\hline
\end{tabular}


Universal Copyright Convention

Geneva, 6 September 1952, revised Paris, 24 July 1971

Entry into force: 16 September 1955 (revision: 10 July 1974)

(Status as provided by UNESCO on 18 April 1997)

\begin{tabular}{|c|c|c|c|c|c|}
\hline State & Cons. (deposit) & Cons. (rev.) & State & Cons. (deposit) & Cons. (rev.) \\
\hline Bangladesh & 5 May 75 & & Korea (Rep.) & 1 Jul 87 & \\
\hline Cambodia & 3 Aug 53 & & Laos & 19 Aug 54 & \\
\hline China & 30 Jul 92 & & Pakistan & 28 Apr 54 & \\
\hline India & 21 Oct 57 & 7 Jan 88 & Sri Lanka & 25 Oct 83 & \\
\hline Japan & $28 \operatorname{Jan} 56$ & & Tajikistan & 28 Aug 92 & \\
\hline Kazakhstan & 6 Aug 92 & & & & \\
\hline
\end{tabular}

Protocol 1 annexed to the Universal Copyright Convention concerning the application of the Convention to the works of stateless persons and refugees

Geneva, 6 September 1952 (revised Paris, 24 July 1971)

Entry into force: 16 September 1955 (revision: 10 July 1974)

(Status as provided by UNESCO on 18 April 1997)

$\begin{array}{llllll}\text { State } & \text { Cons. (deposit) } & \text { Cons. (rev.) } & \text { State } & \text { Cons. (deposit) } & \text { Cons. (rev.) } \\ \text { Bangladesh } & \text { 5 May 75 } & & \text { Korea (Rep.) } & \text { 1 Jul 87 } \\ \text { Cambodia } & \text { 3 Aug 53 } & & \text { Laos } & \text { 19 Aug 54 } \\ \text { India } & \text { 21 Oct 57 } & \text { 7 Jan 88 } & \text { Pakistan } & \text { 28 Apr 54 } \\ \text { Japan } & \text { 28 Jan 56 } & \text { 21 Jul 77 } & \text { Sri Lanka } & \text { 27 Jul 88 }\end{array}$

Protocol 2 annexed to the Universal Copyright Convention concerning the application of the Convention to the works of certain international organizations

Geneva, 6 September 1952 (revised Paris, 24 July 1971)

Entry into force: 16 September 1955 (revision: 20 July 1974)

(Status as provided by UNESCO on 18 April 1997)

\begin{tabular}{|c|c|c|c|c|c|}
\hline State & Cons. (deposit) & Cons. (rev.) & State & Cons. (deposit) & Cons. (rev.) \\
\hline Cambodia & 3 Aug 53 & & Laos & 19 Aug 54 & \\
\hline India & 21 Oct 57 & 7 Jan 88 & Pakistan & 28 Apr 54 & \\
\hline Japan & $28 \operatorname{Jan} 56$ & 21 Jul 77 & Sri Lanka & 27 Jul 88 & \\
\hline
\end{tabular}

Protocol 3 annexed to the Universal Copyright Convention concerning the effective date of instruments of ratification or acceptance of, or accession to, the Convention

Geneva, 6 September 1952

Entry into force: 7 August 1956

(Status as provided by UNESCO on 18 April 1997)

$\begin{array}{llll}\text { State } & \text { Cons. (deposit) } & \text { State } & \text { Cons. (deposit) } \\ \text { Cambodia } & \text { 3 Aug 53 } & \text { Pakistan } & \text { 28 Apr } 54 \\ \text { India } & \text { 21 Oct 57 } & \text { Sri Lanka } & \text { 27 Jul } 88 \\ \text { Japan } & \text { 28 Jan 56 } & & \\ \text { Laos } & \text { 19 Aug 54 } & & \end{array}$


International Convention for the Protection of Performers, Producers of Phonograms and Broadcasting Organizations

Rome, 26 October 1961

Entry into force: 18 May 1964

(Status as included in WIPO Doc. 432(E) of 3 July 1997)

$\begin{array}{lllc}\text { State } & \text { Cons. (deposit) } & \text { State } & \begin{array}{l}\text { Cons. } \\ \text { (deposit) }\end{array} \\ \text { Japan } & 26 \mathrm{Jul} 89 & \text { Philippines } & 25 \text { Jun } 84\end{array}$

\section{Convention Establishing the World Intellectual Property Organization} Stockholm, 14 July 1967

(Status as included in WIPO doc. 423(E) of 3 July 1997)

State

Membership State

Bangladesh

Bhutan

Brunei

Cambodia

China

India

Indonesia

Japan

Kazakhstan

Korea (DPR)

Korea (Rep.)

Kyrgyzstan

Laos

\section{May 85}

16 Mar 94

21 Apr 94

25 Jul 95

3 Jun 80

1 May 75

18 Dec 79

20 April 75

25 Dec 91

17 Aug 74

1 Mar 79

25 Dec 91

17 Jan 95

Malaysia
Mongolia
Nepal
Pakistan
Papua New Guinea
Philippines
Singapore
Sri Lanka
Tajikistan
Thailand
Turkmenistan
Uzbekistan
Vietnam

Membership

1 Jan 89

28 Feb 79

4 Feb 97

6 Jan 77

10 Jul 97

14 Jul 80

$10 \operatorname{Dec} 90$

20 Sep 78

25 Dec 91

25 Dec 89

$25 \operatorname{Dec} 91$

25 Dec 91

2 Jul 76

\section{Convention for the Protection of Producers of Phonograms against}

Unauthorized Duplication of their Phonograms, 1971

Geneva, 29 October 1971

Entry into force: 18 April 1973

$\begin{array}{llllll}\text { State } & \text { Sig. } & \text { Cons. } & \text { State } & \text { Sig. } & \text { Cons. } \\ \text { China } & \cdot & 5 \text { Jan } 93 & \text { Japan } & 21 \text { Apr } 72 & \text { 19 Jun } 78 \\ \text { India } & 29 \text { Oct } 71 & 1 \text { Nov } 74 & \begin{array}{l}\text { Korea (Rep.) } \\ \text { Philippines }\end{array} & 29 \text { Apr 72 } & 1 \text { Jul } 87 \\ \text { Iran } & 29 \text { Oct 71 } & & \text { ran }\end{array}$

Multilateral Convention for the Avoidance of Double Taxation of Copyright Royalties

Madrid, 13 December 1979

Entry into force: -

$\begin{array}{ll}\text { State } & \text { Cons. } \\ \text { India } & 31 \mathrm{Jan} 83 \text { (except Arts. } 1 \text { to } 4 \text { and 17) }\end{array}$ 


\section{INTERNATIONAL CRIMES}

\section{Slavery Convention}

Geneva, 25 September 1926 as amended in New York, 7 December 1953

Entry into force: 7 July 1955

$\begin{array}{llllll}\text { State } & \text { Sig. } & \text { Cons. } & \text { State } & \text { Sig. } & \text { Cons. } \\ \begin{array}{l}\text { Afghanistan } \\ \text { Bangladesh }\end{array} & \text { 16 Aug 54 } & & \text { Pakistan } & \text { 70 Sep 55 } \\ \begin{array}{l}\text { India } \\ \text { Mongolia }\end{array} & \text { 12 Mar 54 } & & \text { Papua } & \text { New Guinea } & \text { 27 Jan 82 } \\ \begin{array}{l}\text { Myanmar } \\ \text { Nepal }\end{array} & \text { 29 Apr 57 } & \text { 20 Dec 68 } & \begin{array}{l}\text { Philippines } \\ \text { Sri Lanka }\end{array} & \text { 12 Jul 55 } \\ \text { 21 Mar 58 }\end{array}$

Convention on the Prevention and Punishment of the Crime of Genocide

New York, 9 December 1948

Entry into force: 12 January 1951

\begin{tabular}{|c|c|c|c|c|c|}
\hline State & Sig. & Cons. & State & Sig. & Cons. \\
\hline Afghanistan & & 22 Mar 56 & Mongolia & & 5 Jan 67 \\
\hline Cambodia & & 14 Oct 50 & Myanmar & $30 \operatorname{Dec} 49$ & $14 \operatorname{Mar} 56$ \\
\hline China & $20 \mathrm{Jul} 49$ & $18 \mathrm{Apr} 83$ & Nepal & & 17 Jan 69 \\
\hline India & 29 Nov 49 & 27 Aug 59 & Pakistan & $11 \operatorname{Dec} 48$ & 12 Oct 57 \\
\hline Iran & 8 Dec 49 & 14 Aug 56 & Papua New & & 27 Jan 82 \\
\hline Korea (DPR) & & $31 \operatorname{Jan} 89$ & Philippines & $11 \operatorname{Dec} 48$ & 7 Jul 50 \\
\hline Korea (Rep.) & & 14 Oct 50 & Singapore & & 18 Aug 95 \\
\hline Laos & & $8 \operatorname{Dec} 50$ & Sri Lanka & & 2 Oct 50 \\
\hline Malaysia & & 20 Dec 94 & Vietnam & & 9 Jun 81 \\
\hline Maldives & & 24 Apr 84 & & & \\
\hline
\end{tabular}

Supplementary Convention on the Abolition of Slavery, the Slave Trade, and Institutions and Practices Similar to Slavery

Geneva, 7 September 1956

Entry into force: 30 April 1957

$\begin{array}{llllll}\text { State } & \text { Sig. } & \text { Cons. } & \text { State } & \text { Sig. } & \text { Cons. } \\ \text { Afghanistan } & & 16 \text { Nov 66 } & \text { Mongolia } & & \text { 20 Dec 68 } \\ \text { Bangladesh } & & \text { 5 Feb 85 } & \text { Nepal } & & \text { 7 Jan 63 } \\ \text { Cambodia } & & \text { 12 Jun 57 } & \text { Pakistan } & \text { 7 Sep 56 } & \text { 20 Mar 58 } \\ \text { India } & \text { 7 Sep 56 } & \text { 23 Jun 60 } & \text { Philippines } & & \text { 17 Nov 64 } \\ \text { Iran } & & \text { 30 Dec 59 } & \text { Singapore } & & \text { 28 Mar 72 } \\ \text { Laos } & & 9 \text { Sep 57 } & \text { Sri Lanka } & \text { 5 Jun 57 } & \text { 21 Mar 58 } \\ \text { Malaysia } & & \text { 18 Nov 57 } & & & \end{array}$

Convention on Offences and Certain Other Acts Committed on Board Aircraft

Tokyo, 14 September 1963

Entry into force: 4 December 1969

(Status as at 30 June 1997, provided by the ICAO Secretariat) 


$\begin{array}{llllll}\text { State } & \text { Cons. } & \text { Eff. date } & \text { State } & \text { Cons. } & \text { Eff. date } \\ \text { Afghanistan } & \text { 15 Apr 77 } & \text { 14 Jul 77 } & \text { Maldives } & \text { 28 Sep 87 } & \text { 27 Dec 87 } \\ \text { Bangladesh } & \text { 25 Jul 78 } & \text { 23 Oct 78 } & \text { Mongolia } & \text { 24 Jul 90 } & \text { 22 Oct 90 } \\ \text { Bhutan } & \text { 25 Jan 89 } & \text { 25 Apr 89 } & \text { Myanmar } & \text { 23 May 96 } & \text { 21 Aug 96 } \\ \text { Brunei } & \text { 23 May 86 } & \text { 21 Aug 86 } & \text { Nepal } & \text { 15 Jan 79 } & \text { 15 Apr.79 } \\ \text { Cambodia } & \text { 22 Oct 96 } & \text { 20 Jan 97 } & \text { Pakistan } & \text { 11 Sep 73 } & \text { 10 Dec 73 } \\ \text { China } & \text { 14 Nov 78 } & \text { 12 Feb 79 } & \text { Papua New } & & \\ \text { India } & \text { 22 Jul 75 } & \text { 20 Oct 75 } & \text { Guinea } & \text { 15 Dec 75 } & \text { 16 Sep 75 } \\ \text { Indonesia } & \text { 7 Sep 76 } & \text { 6 Dec 76 } & \text { Philippines } & \text { 26 Nov 65 } & \text { 4 Dec 69 } \\ \text { Iran } & \text { 28 Jun 76 } & \text { 29 Sep 76 } & \text { Seychelles } & \text { 4 Jan 79 } & \text { 4 Apr 79 } \\ \text { Japan } & \text { 26 May 70 } & \text { 24 Aug 70 } & \text { Singapore } & \text { 1 Mar 71 } & \text { 30 May 71 } \\ \text { Kazakhstan } & \text { 18 May 95 } & \text { 16 Aug 95 } & \text { Sri Lanka } & \text { 30 May 78 } & \text { 28 Aug 78 } \\ \text { Korea (DPR) } & \text { 9 May 83 } & \text { 7 Aug 83 } & \text { Tajikistan } & \text { 20 Mar 96 } & \text { 18 Jun 96 } \\ \text { Korea (Rep.) } & \text { 19 Feb 71 } & \text { 20 May 71 } & \text { Thailand } & \text { 6 Mar 72 } & \text { 4 Jun 72 } \\ \text { Laos } & \text { 23 Oct 72 } & \text { 21 Jan 73 } & \text { Uzbekistan } & \text { 31 Jul 95 } & \text { 20 Oct 95 } \\ \text { Malaysia } & \text { 5 Mar 85 } & \text { 3 Jun 85 } & \text { Vietnam } & \text { 10 Oct 79 } & \text { 8 Jan 80 }\end{array}$

Convention on the Non-Applicability of Statutory Limitations to War Crimes and Crimes Against Humanity

New York, 26 November 1968

Entry into force: 11 November 1970

$\begin{array}{llllll}\text { State } & \text { Sig. } & \text { Cons. } & \text { State } & \text { Sig. } & \text { Cons. } \\ \text { Afghanistan } & & \text { 22 Jul 83 } & \text { Mongolia } & \text { 31 Jan 69 } & \text { 21 May 69 } \\ \text { India } & \text { 12 Jan 71 } & \text { Philippines } & & \text { 15 May 73 } \\ \text { Korea (DPR) } & & 8 \text { Nov 84 } & \text { Vietnam } & & 6 \text { May 83 } \\ \text { Laos } & 28 \text { Dec } 84 & & \end{array}$

Convention for the Suppression of Unlawful Seizure of Aircraft

The Hague, 16 December 1970

Entry into force: 14 October 1971

(Status as at 30 June 1997, provided by the ICAO Secretariat)

\begin{tabular}{|c|c|c|c|c|c|}
\hline State & Sig. & Cons. & State & Sig. & Cons. \\
\hline Afghanistan & $16 \operatorname{Dec} 70$ & 29 Aug 79 & Maldives & & 1 Sep 87 \\
\hline Bangladesh & & 28 Jun 78 & Mongolia & $18 \mathrm{Jan} 71$ & 8 Oct 71 \\
\hline Bhutan & & $28 \operatorname{Dec} 88$ & Myanmar & & 22 May 96 \\
\hline Brunei & & 16 Apr 86 & Nepal & & $11 \mathrm{Jan} 79$ \\
\hline Cambodia & $16 \operatorname{Dec} 70$ & 8 Nov 96 & Pakistan & 12 Aug 71 & 28 Nov 73 \\
\hline China & & 10 Sep 80 & Papua & & \\
\hline India & 14 Jul 71 & 12 Nov 82 & New Guinea & $15 \operatorname{Dec} 75$ & \\
\hline Indonesia & $16 \operatorname{Dec} 70$ & 27 Aug 76 & Philippines & $16 \operatorname{Dec} 70$ & $26 \mathrm{Mar} 73$ \\
\hline Iran & $16 \mathrm{Dec} 70$ & 25 Jun 72 & Seychelles & $29 \operatorname{Dec} 78$ & \\
\hline Japan & $16 \operatorname{Dec} 70$ & 19 Apr 71 & Singapore & $8 \operatorname{Sep} 71$ & 12 Apr 78 \\
\hline Kazakhstan & & 4 Apr 95 & Sri Lanka & 30 May 78 & \\
\hline Korea (DPR) & & 28 Apr 83 & Tajikistan & & 29 Feb 96 \\
\hline Korea (Rep.) & & $18 \operatorname{Jan} 73$ & Thailand & $16 \operatorname{Dec} 70$ & 16 May 78 \\
\hline Laos & 16 Feb 71 & 6 Apr 89 & Uzbekistan & & 7 Feb 94 \\
\hline Malaysia & $16 \operatorname{Dec} 70$ & 4 May 85 & Vietnam & & 17 Sep 79 \\
\hline
\end{tabular}

Convention for the Suppression of Unlawful Acts Against the Safety of Civil Aviation

Montreal, 23 September 1971

Entry into force: 26 January 1973

(Status as at 30 June 1997, provided by the ICAO Secretariat) 


\begin{tabular}{|c|c|c|c|c|c|}
\hline State & Sig. & Cons. & State & Sig. & Cons. \\
\hline Afghanistan & & 26 Sep 84 & Malaysia & & 4 May 85 \\
\hline Bangladesh & & 28 Jun 78 & Maldives & & 1 Sep 87 \\
\hline Bhutan & & 28 Dec 88 & Mongolia & 18 Feb 72 & $14 \operatorname{Sep} 72$ \\
\hline Brunei & & 16 Apr 86 & Myanmar & & 22 May 96 \\
\hline Cambodia & & 8 Nov 96 & Nepal & & $11 \mathrm{Jan} 79$ \\
\hline China & & 10 Sep 80 & Pakistan & & $24 \mathrm{Jan} 74$ \\
\hline India & $11 \operatorname{Dec} 72$ & 12 Nov 82 & Papua New & & $15 \operatorname{Dec} 75$ \\
\hline Indonesia & & 27 Aug 76 & Philippines & $23 \operatorname{Sep} 71$ & $26 \operatorname{Mar} 73$ \\
\hline Iran & & 10 Jul 73 & Singapore & 21 Nov 72 & 12 Apr 78 \\
\hline Japan & & 12 Jun 74 & Sri Lanka & & 30 May 78 \\
\hline Kazakhstan & & 4 Apr 95 & Tajikistan & & 29 Feb 96 \\
\hline Korea (DPR) & & 13 Aug 80 & Thailand & & 16 May 78 \\
\hline Korea (Rep.) & & 2 Aug 73 & Uzbekistan & & 7 Feb 94 \\
\hline Laos & 1 Nov 72 & 6 Apr 89 & Vietnam & & 17 Sep 79 \\
\hline
\end{tabular}

Convention on the Prevention and Punishment of Crimes Against Internationally Protected Persons Including Diplomatic Agents

New York, 14 December 1973

Entry into force: 20 February 1977

\begin{tabular}{|c|c|c|c|c|c|}
\hline State & Sig. & Cons. & State & Sig. & Cons. \\
\hline Bhutan & & 16 Jan 89 & Korea (Rep.) & & 25 May 83 \\
\hline China & & 5 Aug 87 & Maldives & & 21 Aug 90 \\
\hline India & & $11 \mathrm{Apr} 78$ & Mongolia & 23 Aug 74 & 8 Aug 75 \\
\hline Iran & & 12 Jul 78 & Nepal & & $9 \operatorname{Mar} 90$ \\
\hline Japan & & 8 Jun 87 & Pakistan & & 29 Mar 76 \\
\hline Kazakhstan & & $21 \mathrm{Feb} 96$ & Philippines & & 26 Nov 76 \\
\hline Korea (DPR) & & $1 \mathrm{Dec} 82$ & Sri Lanka & & 27 Feb 91 \\
\hline
\end{tabular}

International Convention on the Suppression and Punishment of the Crime of Apartheid New York, 30 November 1973

Entry into force: 18 July 1976

$\begin{array}{lllll}\text { State } & \text { Cons. } & \text { State } & \text { Sig. } & \text { Cons. } \\ \text { Afghanistan } & 6 \text { Jul 83 } & \text { Maldives } & & \text { 24 Apr 84 } \\ \text { Bangladesh } & 5 \text { Feb 85 } & \text { Mongolia } & \text { 17 May 74 } & \text { 8 Aug 75 } \\ \text { Cambodia } & 28 \text { Jul 81 } & \text { Nepal } & & \text { 12 Jul 77 } \\ \text { China } & \text { 18 Apr 83 } & \text { Pakistan } & & \text { 27 Feb 86 } \\ \text { India } & 22 \text { Sep 77 } & \text { Philippines } & \text { 2 May 74 } & \text { 26 Jan 78 } \\ \text { Iran } & 17 \text { Apr 85 } & \text { Sri Lanka } & & \text { 18 Feb 82 } \\ \text { Laos } & 5 \text { Oct } 81 & \text { Vietnam } & & \text { 9 Jun 81 }\end{array}$

\section{International Convention Against the Taking of Hostages}

New York, 17 December 1979

Entry into force: 3 June 1983

$\begin{array}{llllll}\text { State } & \text { Sig. } & \text { Cons. } & \text { State } & \text { Sig. } & \text { Cons. } \\ \text { Bhutan } & & \text { 31 Aug 81 } & \text { Kazakhstan } & & 21 \text { Feb } 96 \\ \text { Brunei } & & \text { 18 Oct 88 } & \text { Korea (Rep.) } & & 4 \text { May } 83 \\ \text { China } & & \text { 26 Jan 93 } & \text { Mongolia } & & 9 \text { Jun 92 } \\ \text { India } & & \text { 7 Sep 94 } & \text { Nepal } & & 9 \text { Mar } 90 \\ \text { Japan } & 22 \text { Dec } 80 & \text { 8 Jun 87 } & \text { Philippines } & \text { 2 May 80 } & \text { 14 Oct } 80\end{array}$


Convention for the Suppression of Unlawful Acts Against the Safety of Maritime Navigation

Rome, 10 March 1988

Entry into force: 1 March 1992

(Status as included in IMO doc. J/6233, as at 31 December 1995)

State Sig. Cons.

China 20 Aug $91 \quad 1$ Mar 1992

Protocol for the Suppression of Unlawful Acts Against the Safety of Fixed Platforms Located on the Continental Shelf Rome, 10 March 1988

Entry into force: 1 March 1992

(Status as included in IMO doc. J/6233, as at 31 December 1995)

$\begin{array}{llllll}\text { State } & \text { Sig. } & \text { Cons. } & \text { State } & \text { Sig. } & \text { Cons. } \\ \text { Brunei } & 3 \text { Feb } 89 & & \text { Philippines } & 10 \text { Mar } 88 & \\ \text { China } & \text { 20 Aug 91 } & \text { 1 Mar 92 } & & & \end{array}$

Protocol for the Suppression of Unlawful Acts of Violence at Airports Serving International Civil Aviation, Supplementary to the Convention for the Suppression of Unlawful Acts Against the Safety of Civil Aviation

Montreal, 24 February 1988

Entry into force: 6 August 1989

(Status as at 30 June 1997, provided by the Secretariat of the ICAO)

\begin{tabular}{|c|c|c|c|c|c|}
\hline State & Cons. & Effective date & State & Cons. & Effective date \\
\hline Cambodia & 8 Nov 96 & 8 Dec 96 & Pakistan & 24 Feb 88 & \\
\hline China & 24 Feb 88 & & Philippines & $25 \mathrm{Jan} 89$ & \\
\hline India & 22 Mar 95 & 21 Apr 95 & Singapore & 22 Nov 96 & 22 Dec 96 \\
\hline Indonesia & 24 Feb 88 & & Sri Lanka & 11 Feb 97 & $13 \operatorname{Mar} 97$ \\
\hline Kazakhstan & 18 May 95 & 17 Jun 95 & Sri Lanka & & 28 Oct 88 \\
\hline Korea (DPR) & 11 Apr 89 & & Tajikistan & 29 Feb 96 & 30 Mar 96 \\
\hline Korea (Rep.) & 27 Jun 90 & $27 \mathrm{Jul} 90$ & Thailand & 14 May 96 & 13 Jun 96 \\
\hline Malaysia & $24 \mathrm{Feb} 88$ & & Uzbekistan & 7 Feb 94 & 9 Mar 94 \\
\hline Myanmar & 22 May 96 & 21 Jun 96 & & & \\
\hline
\end{tabular}

International Convention against the Recruitment, Use, Financing and

Training of Mercenaries

New York, 4 December 1989

Entry into force: -

$\begin{array}{llllll}\text { State } & \text { Sig. } & \text { Cons. } & \text { State } & \text { Sig. } & \text { Cons. } \\ \text { Maldives } & 17 \text { Jul 90 } & 11 \text { Sep 91 } & \text { Turkmenistan } & & 18 \text { Sep 96 }\end{array}$

Convention on the Marking of Plastic Explosives for the Purpose of Detection Montreal, 1 March 1991

Entry into force: -

(Status as at 30 June 1996, provided by the Secretariat of the ICAO on 18 April 1997)

$\begin{array}{llllll}\text { State } & \text { Sig. } & \text { Cons. } & \text { State } & \text { Sig. } & \text { Cons. } \\ \text { Afghanistan } & 1 \text { Mar 91 } & & \text { Korea (Rep.) } & 1 \text { Mar 91 } & \\ \text { Kazakhstan } & & \text { 18 May 95 } & \text { Pakistan } & 1 \text { Mar 91 }\end{array}$




\section{INTERNATIONAL REPRESENTATION \\ (see also: Privileges and Immunities)}

Vienna Convention on the Representation of States in their relations with International Organizations of a Universal Character

Vienna, 14 March 1975

Entry into force: -

$\begin{array}{llllll}\text { State } & \text { Sig. } & \text { Cons. } & \text { State } & \text { Sig. } & \text { Cons. } \\ \text { Iran } & & 30 \text { Dec } 88 & \text { Mongolia } & 30 \text { Oct 75 } & 14 \text { Dec 76 } \\ \text { Korea (DPR) } & & 14 \text { Dec } 82 & \text { Vietnam } & & 26 \text { Aug 80 }\end{array}$

\section{INTERNATIONAL TRADE}

Convention on the Limitation Period in the International Sale of Goods New York, 14 June 1974

Entry into force: 1 August 1988

State Sig. Cons.

Mongolia $\quad 14$ Jun 74

Convention on Transit Trade of Land-locked States

New York, 8 July 1965

Entry into force: 9 June 1967

$\begin{array}{llllll}\text { State } & \text { Sig. } & \text { Cons. } & \text { State } & \text { Sig. } & \text { Cons. } \\ \text { Afghanistan } & \text { 8 Jul 65 } & & \text { Nepal } & \text { 9 Jul 65 } & \text { 22 Aug 66 } \\ \text { Laos } & \text { 8 Jul 65 } & \text { 29 Dec 67 } & \text { Uzbekistan } & & \text { 7 Feb 96 } \\ \text { Mongolia } & & \text { 26 Jul 66 } & & & \end{array}$

UN Convention on Contracts for the International Sale of Goods, 1980

Vienna, 1980

Entry into force: 1 January 1988

(Status as provided in UNCITRAL doc. A/CN.9/440, 22 May 1997)

\begin{tabular}{|c|c|c|c|c|}
\hline \multirow{4}{*}{$\begin{array}{l}\text { State } \\
\text { China } \\
\text { Singapore }\end{array}$} & Sig. & Cons. & State & Cons. \\
\hline & 30 Sep 81 & $11 \operatorname{Dec} 86$ & \multirow[t]{2}{*}{ Uzbekistan } & \multirow[t]{3}{*}{27 Nov 96} \\
\hline & 11 Apr 80 & 16 Feb 95 & & \\
\hline & \multicolumn{3}{|c|}{$\begin{array}{l}\text { UN Convention on the Liability of Operators of Transport Terminals } \\
\text { in International Trade } \\
\text { Vienna, 19 April 1991 } \\
\text { Entry into force: - }\end{array}$} & \\
\hline State & Sig. & Cons. & & \\
\hline Philippines & 19 Apr 91 & & & \\
\hline
\end{tabular}




\section{JUDICIAL AND ADMINISTRATIVE COOPERATION}

\section{Convention Relating to Civil Procedure}

The Hague, 1 March 1954

Entry into force: 12 April 1957

(Status as on 5 June 1997 as furnished by the Permanent Bureau of the Hague Conference on Private International Law)

$\begin{array}{llllll}\text { State } & \text { Sig. } & \text { Cons. } & \text { State } & \text { Sig. } & \text { Cons. } \\ \text { Japan } & \text { 12 Mar 70 } & \begin{array}{l}\text { 28 May 70 } \\ \text { 16 Jun 97 }\end{array} & \text { Uzbekistan } & & 4 \text { Oct 96 } \\ \text { Kyrgyzstan } & & & & \end{array}$

\section{Convention Abolishing the Requirement of Legalisation for Foreign Public Documents} The Hague, 5 October 1961

Entry into force: 24 January 1965

(Status on 5 June 1997 as furnished by the Permanent Bureau of the Hague Conference on Private International Law)

State Sig. $\quad$ Cons.

State

Sig.

Cons.

Brunei

23 Feb 87

Japan

$12 \operatorname{Mar} 70$

28 May 70

Convention on the Service Abroad of Judicial and Extrajudicial Documents in Civil or Commercial Matters, 1965

The Hague, 15 November 1965

Entry into force: 10 February 1969

(Status on 5 June 1997 as furnished by the Permanent Bureau of the Hague Conference on Private International Law)

$\begin{array}{llllll}\text { State } & \text { Sig. } & \text { Cons. } & \text { State } & \text { Sig. } & \text { Cons. } \\ \text { China } & & 1 \text { Dec } 91 & \text { Pakistan } & & \text { 6 Jul } 89 \\ \text { Japan } & \text { 12 Mar 70 } & \text { 28 May 70 } & & & \end{array}$

Convention on the Taking of Evidence Abroad in Civil or Commercial Matters

The Hague, 18 March 1970

Entry into force: 7 October 1972

(Status on 5 June 1997 as furnished by the Permanent Bureau of the Hague Conference on Private International Law)

State

Sig. $\quad$ Cons.

Singapore

27 Oct 78

\section{LABOUR}

Forced Labour Convention

1930 (ILO Convention 29)

Entry into force: 1 May 1932

(Status as at 31 December 1996, information furnished by the ILO) 


$\begin{array}{llll}\text { State } & \text { Ratif. registered } & \text { State } & \text { Ratif. registered } \\ \text { Bagladesh } & \text { 22 Jun 72 } & \text { Myanmar } & \text { 4 Mar 55 } \\ \text { Cambodia } & \text { 24 Feb 69 } & \text { Pakistan } & \text { 23 Dec } 57 \\ \text { India } & \text { 30 Nov 54 } & \text { Papua New } & \\ \text { Indonesia } & \text { 12 Jun 50 } & \text { Guinea } & \text { 1 May } 76 \\ \text { Iran } & \text { 10 Jun 57 } & \text { Singapore } & \text { 25 Oct } 65 \\ \text { Japan } & \text { 21 Nov 32 } & \text { Sri Lanka } & \text { 5 Apr 50 } \\ \text { Kyrgyzstan } & \text { 31 Mar 92 } & \text { Tajikistan } & \text { 26 Nov 93 } \\ \text { Laos } & \text { 23 Jan } 64 & \text { Thailand } & \text { 26 Feb 69 } \\ \text { Malaysia } & \text { 11 Nov 57 } & & \end{array}$

Freedom of Association and Protection of the Right to Organise Convention 1948 (ILO Convention 87)

Entry into force: 4 July 1950

(Status as at 31 December 1996, information furnished by the ILO)

$\begin{array}{llll}\text { State } & \text { Ratif. registered } & \text { State } & \text { Ratif. registered } \\ \text { Bangladesh } & \text { 22 Jun 72 } & \text { Pakistan } & \text { 14 Feb 51 } \\ \text { Japan } & \text { 14 Jun 65 } & \text { Philippines } & \text { 29 Dec 53 } \\ \text { Kyrgyzstan } & \text { 31 Mar 92 } & \text { Sri Lanka } & \text { 15 Sep 95 } \\ \text { Mongolia } & \text { 3 Jun 69 } & \text { Tajikistan } & \text { 26 Nov 93 } \\ \text { Myanmar } & \text { 4 Mar 55 } & & \end{array}$

Right to Organise and Collective Bargaining Convention 1949 (ILO Convention 98)

Entry into force: 18 July 1951

(Status as at 31 December 1996, information furnished by the ILO)

$\begin{array}{llll}\text { State } & \text { Ratif. registered } & \text { State } & \text { Ratif. registered } \\ \text { Bangladesh } & \text { 22 Jun } 72 & \text { Pakistan } & 26 \text { May } 52 \\ \text { Indonesia } & \text { 15 Jul } 57 & \text { Papua New } & \\ \text { Japan } & \text { 20 Oct } 53 & \text { Guinea } & 1 \text { May } 76 \\ \text { Kyrgyzstan } & \text { 31 Mar } 92 & \text { Philippines } & 29 \text { Dec } 53 \\ \text { Malaysia } & \text { 5 Jun } 61 & \text { Singapore } & 25 \text { Oct } 65 \\ \text { Mongolia } & \text { 3 Jun } 69 & \text { Sri Lanka } & 13 \text { Dec } 72 \\ \text { Nepal } & \text { 11 Nov } 96 & \text { Tajikistan } & \text { 26 Nov } 93\end{array}$

Equal Remuneration Convention

1951 (ILO Convention 100)

Entry into force: 23 May 1953

(Status as at 31 December 1996, information furnished by the ILO)

$\begin{array}{llll}\text { State } & \text { Ratif. registered } & \text { State } & \text { Ratif. registered } \\ \text { Afghanistan } & \text { 22 Aug 69 } & \text { Kyrgyzstan } & \text { 31 Mar } 92 \\ \text { China } & 2 \text { Nov } 90 & \text { Mongolia } & \text { 3 Jun } 69 \\ \text { India } & 25 \text { Sep 58 } & \text { Nepal } & \text { 10 Jun } 76 \\ \text { Indonesia } & \text { 11 Aug 58 } & \text { Philippines } & \text { 29 Dec 53 } \\ \text { Iran } & \text { 10 Jun 72 } & \text { Sri Lanka } & \text { 1 Apr } 93 \\ \text { Japan } & \text { 24 Aug 67 } & \text { Tajikistan } & \text { 26 Nov 93 }\end{array}$




\section{Abolition of Forced Labour Convention \\ 1957 (ILO Convention 105) \\ Entry into force: 17 January 1959}

(Status as at 31 December 1996, information furnished by the ILO)

$\begin{array}{llll}\text { State } & \text { Ratif. registered } & \text { State } & \text { Ratif. registered } \\ \text { Afghanistan } & \text { 16 May 63 } & \text { Papua New } & \\ \text { Bangladesh } & \text { 22 Jun 72 } & \text { Guinea } & 1 \text { May } 76 \\ \text { Iran } & \text { 13 Apr 59 } & \text { Philippines } & 17 \text { Nov 60 } \\ \text { Pakistan } & \text { 15 Feb 60 } & \text { Thailand } & \text { 2 Dec 69 }\end{array}$

Discrimination (Employment and Occupation) Convention 1958 (ILO Convention 111)

Entry into force: 15 June 1960

(Status as at 31 December 1996, information furnished by the ILO)

$\begin{array}{llll}\text { State } & \text { Ratif. registered } & \text { State } & \text { Ratif. registered } \\ \text { Afghanistan } & \text { 1 Oct 69 } 69 & \text { Mongolia } & \text { 3 Jun } 69 \\ \text { Bangladesh } & \text { 22 Jun 72 } & \text { Nepal } & \text { 19 Sep 74 } \\ \text { India } & \text { 3 Jun 60 } & \text { Pakistan } & \text { 24 Jan } 61 \\ \text { Iran } & \text { 30 Jun 64 } & \text { Philippines } & \text { 17 Nov } 60 \\ \text { Kyrgyzstan } & \text { 31 Mar 92 } & \text { Tajikistan } & \text { 26 Nov 93 }\end{array}$

\section{Employment Policy Convention \\ 1964 (ILO Convention 122) \\ Entry into force: 15 July 1966}

(Status as at 31 December 1996, information furnished by the ILO)

$\begin{array}{llll}\text { State } & \text { Ratif. registered } & \text { State } & \text { Ratif. registered } \\ \text { Cambodia } & \text { 28 Sep 71 } & \text { Papua } & \\ \text { Iran } & \text { 10 Jun 72 } & \text { New Guinea } & \text { 1 May 76 } \\ \text { Japan } & \text { 10 Jun 86 } & \text { Philippines } & \text { 13 Jan 76 } \\ \text { Korea (Rep.) } & \text { 9 Dec } 92 & \text { Tajikistan } & \text { 26 Nov } 93 \\ \text { Kyrgyzstan } & \text { 31 Mar 92 } & \text { Thailand } & \text { 26 Feb } 69 \\ \text { Mongolia } & \text { 24 Nov 76 } & \text { Uzbekistan } & \text { 13 Jul 92 }\end{array}$

\section{NARCOTIC DRUGS}

\section{International Opium Convention}

Geneva, 19 February 1925, amended by Protocol, New York, 11 December 1946

Entry into force: 3 February 1948

\begin{tabular}{|c|c|c|c|c|c|}
\hline State & Sig. & Cons. & State & Sig. & Cons. \\
\hline Afghanistan & $29 \operatorname{Jan} 57$ & & Malaysia & & 21 Aug 58 \\
\hline Cambodia & 3 Oct 51 & & Papua & & \\
\hline India & $11 \operatorname{Dec} 46$ & & New Guinea & & 28 Oct 80 \\
\hline Indonesia & 3 Apr 58 & & Sri Lanka & & 4 Dec 57 \\
\hline Japan & 27 Mar 52 & & Thailand & 27 Oct 47 & \\
\hline Laos & & 7 Oct 50 & & & \\
\hline
\end{tabular}


Agreement Concerning the Suppression of the Manufacture of, Internal Trade in, and Use of, Prepared Opium

Geneva, 11 February 1925, amended by Protocol, New York, 11 December 1946

Entry into force: 27 October 1947

$\begin{array}{llll}\text { State } & \text { Cons. } & \text { State } & \text { Cons. } \\ \text { Cambodia } & 3 \text { Oct } 51 & \text { Laos } & 7 \text { Oct } 50 \\ \text { India } & 11 \text { Oct } 46 & \text { Thailand } & 27 \text { Oct } 47 \\ \text { Japan } & 27 \text { Mar } 52 & & \end{array}$

Convention for Limiting the Manufacture and Regulating the Distribution of Narcotic Drugs

Geneva, 13 July 1931, amended by Protocol, New York, 11 December 1946

Entry into force: 21 November 1947

$\begin{array}{llllll}\text { State } & \text { Sig. } & \text { Cons. } & \text { State } & \text { Sig. } & \text { Cons. } \\ \text { Afghanistan } & 11 \text { Dec } 46 & & \text { Laos } & & 7 \text { Oct } 50 \\ \text { Cambodia } & \text { 3 Oct } 51 & & \text { Malaysia } & & 21 \text { Aug } 58 \\ \text { China } & 11 \text { Dec } 46 & \text { Papua } & & \\ \text { India } & 11 \text { Dec } 46 & \text { New Guinea } & & 28 \text { Oct } 80 \\ \text { Indonesia } & 3 \text { Apr } 58 & \text { Philippines } & \text { 25 May 50 } & \\ \text { Iran } & 11 \text { Dec } 46 & \text { Sri Lanka } & & \text { 4 Dec } 57 \\ \text { Japan } & 27 \text { Mar } 52 & \text { Thailand } & 27 \text { Oct } 47 & \end{array}$

Agreement Concerning the Suppression of Opium Smoking

Bangkok, 27 November 1931, amended by Protocol, New York, 11 December 1946

Entry into force: 27 October 1947

$\begin{array}{llll}\text { State } & \text { Cons. } & \text { State } & \text { Cons. } \\ \text { Cambodia } & 3 \text { Oct } 51 & \text { Laos } & 7 \text { Oct } 50 \\ \text { India } & 11 \text { Dec } 46 & \text { Thailand } & 27 \text { Oct } 47 \\ \text { Japan } & 27 \text { Mar } 52 & & \end{array}$

Protocol Amending the Agreements, Conventions and Protocols on Narcotic Drugs, concluded at The Hague on 23 January 1912, at Geneva on 11 February 1925 and 19 February 1925 and 13 July 1931, at Bangkok on 27 November 1931 and at Geneva on 26 June 1936

New York, 11 December 1946

Entry into force: 11 December 1946

$\begin{array}{llllll}\text { State } & \text { Sig. } & \text { Cons. } & \text { State } & \text { Sig. } & \text { Cons. } \\ \text { Afghanistan } & 11 \text { Dec } 46 & \text { Papua } & & \\ \text { China } & 11 \text { Dec } 46 & \text { New Guinea } & & \text { 28 Oct } 80 \\ \text { India } & 11 \text { Dec } 46 & \text { Philippines } & \text { 11 Dec 46 } & \text { 25 May } 50 \\ \text { Iran } & 11 \text { Dec } 46 & \text { Thailand } & & 27 \text { Oct } 47 \\ \text { Japan } & 27 \text { Mar } 52 & & & \end{array}$


Protocol bringing under International Control Drugs outside the Scope of the Convention of 1931

Paris, 19 November 1948

Entry into force: 1 December 1949

\begin{tabular}{llllll} 
State & Sig. & Cons. & State & Sig. & Cons. \\
Afghanistan & & 19 Nov 48 & Myanmar & 19 Nov 48 & 2 Mar 50 \\
China & & 19 Nov 48 & Pakistan & 21 Nov 48 & 27 Aug 52 \\
India & \multirow{2}{*}{19 Nov 48 } & 10 Nov 50 & Papua & & \\
Indonesia & & 21 Feb 51 & New Guinea & & 28 Oct 80 \\
Japan & & 5 May 52 & Philippines & 10 Mar 49 & 7 Dec 53 \\
Laos & & 7 Oct 50 & Sri Lanka & & 17 Jan 49 \\
Malaysia & & 21 Aug 58 & & &
\end{tabular}

Convention for the Suppression of the Illicit Traffic in Dangerous Drugs

Geneva, 26 June 1936, amended by Protocol, New York, 11 December 1946

Entry into force: 10 October 1947

$\begin{array}{llllll}\text { State } & \text { Sig. } & \text { Cons. } & \text { State } & \text { Sig. } & \text { Cons. } \\ \text { Cambodia } & & 3 \text { Oct } 51 & \text { Japan } & & 7 \text { Sep 55 } \\ \text { China } & 11 \text { Dec } 46 & & \text { Laos } & & \text { 13 Jul 51 } \\ \begin{array}{l}\text { India } \\ \text { Indonesia }\end{array} & 11 \text { Dec 46 } & & \text { Sri Lanka } & & 4 \text { Dec } 57\end{array}$

Protocol for Limiting and Regulating the Cultivation of the Poppy Plant, the Production of, International and Wholesale Trade in, and Use of Opium

New York, 23 June 1953

Entry into force: 8 March 1963

$\begin{array}{llllll}\text { State } & \text { Sig. } & \text { Cons. } & \text { State } & \text { Sig. } & \text { Cons. } \\ \text { Cambodia } & \text { 29 Dec 53 } & \text { 22 Mar 57 } & \text { Pakistan } & \text { 3 Dec 53 } & \text { 10 Mar 55 } \\ \text { India } & \text { 23 Jun 53 } & \text { 30 Apr 54 } & \text { Papua } & & \\ \text { Indonesia } & & \text { 11 Jul 57 } & \text { New Guinea } & & \text { 28 Oct 80 } \\ \text { Iran } & \text { 15 Dec 53 } & \text { 30 Dec 59 } & \text { Philippines } & \text { 23 Jun 53 } & \text { 1 Jun 55 } \\ \text { Japan } & \text { 23 Jun 53 } & \text { 21 Jul 54 } & \text { Sri Lanka } & & \text { 4 Dec 57 } \\ \text { Korea (Rep.) } & \text { 23 Jun 53 } & \text { 29 Apr 58 } & & & \end{array}$

Single Convention on Narcotic Drugs

New York, 30 March 1961

Entry into force: 13 December 1964

\begin{tabular}{|c|c|c|c|c|c|}
\hline State & Sig. & Cons. & State & Sig. & Cons. \\
\hline Afghanistan & 30 Mar 61 & 19 Mar 63 & Malaysia & & 11 Jul 67 \\
\hline Bangladesh & & 25 Apr 75 & Mongolia & & 6 May 91 \\
\hline Brunei & & 25 Nov 87 & Myanmar & 30 Mar 61 & $29 \mathrm{Jul} 63$ \\
\hline Cambodia & 30 Mar 61 & & Pakistan & 30 Mar 61 & $9 \mathrm{Jul} 65$ \\
\hline India & 30 Mar 61 & $13 \operatorname{Dec} 64$ & Papua & & \\
\hline Indonesia & $28 \mathrm{Jul} 61$ & 3 Sep 76 & New Guinea & & 28 Oct 80 \\
\hline Iran & 30 Mar 61 & 30 Aug 72 & Philippines & 30 Mar 61 & 2 Oct 67 \\
\hline Japan & 26 Jul 61 & 13 Jul 64 & Singapore & & $15 \operatorname{Mar} 73$ \\
\hline Korea (Rep.) & 30 Mar 61 & 13 Feb 62 & Sri Lanka & & 11 Jul 63 \\
\hline Kyrgyzstan & & 7 Oct 94 & Thailand & 24 Jul 61 & 31 Oct 61 \\
\hline Laos & & 22 Jun 73 & Turkmenistan & & 21 Feb 96 \\
\hline
\end{tabular}


Protocol amending the Single Convention on Narcotic Drugs, 1961

Geneva, 25 March 1972

Entry into force: 8 August 1975

\begin{tabular}{|c|c|c|c|c|c|}
\hline State & Sig. & Cons. & State & Sig. & Cons. \\
\hline Bangladesh & & $9 \operatorname{Mar} 80$ & Mongolia & & 6 May 91 \\
\hline Brunei & & 25 Nov 87 & Pakistan & $29 \operatorname{Dec} 72$ & \\
\hline Cambodia & $25 \operatorname{Mar} 72$ & & Papua & & \\
\hline India & & $14 \operatorname{Dec} 78$ & New Guinea & & 28 Oct 80 \\
\hline Indonesia & $25 \operatorname{Mar} 72$ & $3 \operatorname{Sep} 76$ & Philippines & $25 \operatorname{Mar} 72$ & 7 Jun 74 \\
\hline Iran & 25 Mar 72 & & Singapore & & 9 Jul 75 \\
\hline Japan & $15 \operatorname{Dec} 72$ & 27 Sep 73 & Sri Lanka & & 29 Jun 81 \\
\hline Korea (Rep.) & $29 \operatorname{Dec} 72$ & $25 \mathrm{Jan} 73$ & Thailand & & $9 \operatorname{Jan} 75$ \\
\hline Malaysia & & 20 Apr 78 & & & \\
\hline
\end{tabular}

Single Convention on Narcotic Drugs as Amended by the Protocol of 25 March 1972 Amending the Single Convention on Narcotic Drugs 1961

New York, 8 August 1975

Entry into force: 8 August 1975

\begin{tabular}{|c|c|c|c|c|c|}
\hline State & Sig. ${ }^{*}$ & Cons. ${ }^{* *}$ & State & Sig. ${ }^{*}$ & Cons. ${ }^{* *}$ \\
\hline Bangladesh & 9 May 80 & & Nepal & & 29 Jun 87 \\
\hline Brunei & 25 Nov 87 & & Papua New & & \\
\hline China & & 23 Aug 85 & Guinea & 28 Oct 80 & \\
\hline India & $14 \operatorname{Dec} 78$ & & Philippines & 7 Jun 74 & \\
\hline Indonesia & 3 Sep 76 & & Singapore & 9 Jul 75 & \\
\hline Japan & 27 Sep 73 & & Sri Lanka & 29 Jun 81 & \\
\hline Korea (Rep.) & $25 \mathrm{Jan} 73$ & & Thailand & $9 \mathrm{Jan} 75$ & \\
\hline Kyrgyzstan & & 7 Oct 94 & Turkmenistan & $21 \mathrm{Feb} 96$ & \\
\hline Malaysia & 20 Apr 78 & & Uzbekistan & & 24 Aug 95 \\
\hline Mongolia & 6 May 91 & & & & \\
\hline
\end{tabular}

\footnotetext{
* Ratification or accession in respect of Protocol 1972 or participation upon deposit of an instrument of ratification or accession to the Convention of 1961 (art. 19 Protocol).

${ }^{* *}$ Ratification or accession in respect of the Convention as amended.
} 
Convention on Psychotropic Substances

Vienna, 21 February 1971

Entry into force: 16 August 1976

\begin{tabular}{|c|c|c|c|c|c|}
\hline State & Sig. & Cons. & State & Sig. & Cons. \\
\hline Afghanistan & & 21 May 85 & Myanmar & & 21 Sep 95 \\
\hline Bangladesh & & 11 Oct 90 & Pakistan & & 9 Jun 77 \\
\hline Brunei & & 24 Nov 87 & Papua & & \\
\hline China & & 23 Aug 85 & New Guinea & & 20 Nov 81 \\
\hline India & & 23 Apr 75 & Philippines & & 7 Jun 74 \\
\hline Indonesia & & 19 Dec 96 & Singapore & & 17 Sep 90 \\
\hline Iran & 21 Feb 71 & & Sri Lanka & & 15 Mar 93 \\
\hline Japan & $21 \operatorname{Dec} 71$ & 31 Aug 90 & Thailand & & 21 Nov 75 \\
\hline Kyrgyzstan & & 7 Oct 94 & Turkmenistan & & $21 \mathrm{Feb} 96$ \\
\hline Korea (Rep.) & & $12 \operatorname{Jan} 78$ & Uzbekistan & & 12 Jul 95 \\
\hline Malaysia & & $22 \mathrm{Jul} 86$ & & & \\
\hline \multicolumn{6}{|c|}{$\begin{array}{l}\text { United Nations Convention Against Illicit Traffic in Narcotic Drugs and } \\
\text { Psychotropic Substances } \\
\text { Vienna, 20 December 1988 } \\
\text { Entry into force: } 11 \text { November } 1990\end{array}$} \\
\hline State & Sig. & Cons. & State & Sig. & Cons. \\
\hline Afghanistan & $20 \operatorname{Dec} 88$ & 14 Feb 92 & Malaysia & $20 \operatorname{Dec} 88$ & 11 May 93 \\
\hline Bangladesh & 14 Apr 89 & 11 Oct 90 & Maldives & 5 Dec 89 & \\
\hline Bhutan & & 27 Aug 90 & Myanmar & & 11 Jun 91 \\
\hline Brunei & 26 Oct 89 & 12 Nov 93 & Nepal & & 24 Jul 91 \\
\hline China & $20 \operatorname{Dec} 88$ & $27 \operatorname{Mar} 90$ & Pakistan & $20 \operatorname{Dec} 89$ & 25 Oct 91 \\
\hline India & & $27 \operatorname{Mar} 90$ & Philippines & $20 \operatorname{Dec} 88$ & 7 Jun 96 \\
\hline Indonesia & 27 Mar 89 & & Sri Lanka & & 6 June 91 \\
\hline Iran & $20 \operatorname{Dec} 88$ & 7 Dec 92 & Tajikistan & & 6 May 96 \\
\hline Japan & 19 Dec 89 & 12 Jun 92 & Turkmenistan & & $21 \mathrm{Feb} 96$ \\
\hline Kyrgyzstan & & 7 Oct 94 & Uzbekistan & & 24 Aug 95 \\
\hline
\end{tabular}

\section{NATIONALITY AND STATELESSNESS}

\section{Convention relating to the Status of Stateless Persons \\ New York, 28 September 1954 \\ Entry into force: 6 June 1960}

$\begin{array}{llllll}\begin{array}{l}\text { State } \\ \text { Korea (Rep.) }\end{array} & \text { Sig. } & \text { Cons. } & \text { State } & \text { Sig. } & \text { Cons. } \\ & & \text { Philippines } & \text { 22 Jun } 55 & \\ \text { Optional Protocol to the } & \text { Vienna Convention on Diplomatic Relations concerning } \\ \text { Acquisition of Nationality } \\ \text { Vienna, 18 April 1961 } \\ \text { Entry into force: 24 April 1964 }\end{array}$




$\begin{array}{llllll}\text { State } & \text { Sig. } & \text { Cons. } & \text { State } & \text { Sig. } & \text { Cons. } \\ \text { Cambodia } & & \text { 31 Aug 65 } & \text { Malaysia } & & 9 \text { Nov 65 } \\ \text { India } & & \text { 15 Oct 65 } & \text { Myanmar } & & 7 \text { Mar } 80 \\ \text { Indonesia } & & \text { 4 Jun 82 } & \text { Nepal } & & \text { 28 Sep 65 } \\ \text { Iran } & \text { 27 May 61 } & \text { 3 Feb 65 } & \text { Philippines } & \text { 20 Oct 61 } & \text { 15 Nov 65 } \\ \text { Korea (Rep.) } & \text { 30 Mar 62 } & \text { 7 Mar 77 } & \text { Sri Lanka } & & \text { 31 Jul 78 } \\ \text { Laos } & & \text { 3 Dec. 62 } & \text { Thailand } & \text { 30 Oct 61 } & \text { 23 Jan 85 }\end{array}$

Optional Protocol to the Vienna Convention on Consular Relations concerning Acquisition of Nationality

Vienna, 24 April 1963

Entry into force: 19 March 1967

$\begin{array}{llllll}\text { State } & \text { Sig. } & \text { Cons. } & \text { State } & \text { Sig. } & \text { Cons. } \\ \text { India } & & 28 \text { Nov 77 } & \text { Laos } & & 9 \text { Aug 73 } \\ \text { Indonesia } & & \text { 4 Jun 82 } & \text { Nepal } & & 28 \text { Sep 65 } \\ \text { Iran } & \text { 5 Jun 75 } & \text { Philippines } & & 15 \text { Nov 65 } \\ \text { Korea (Rep.) } & 7 \text { Mar 77 } & & \end{array}$

\section{NUCLEAR MATERIAL}

Convention on Civil Liability for Nuclear Damage

Vienna, 21 May 1963

Entry into force: 12 November 1977

(Information furnished by IAEA Secretariat)

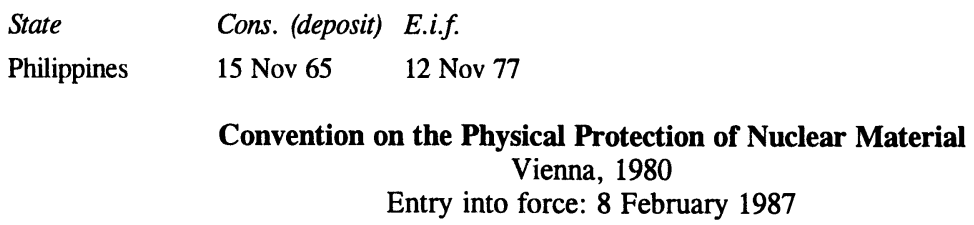

$\begin{array}{llllll}\text { State } & \text { Sig. } & \text { Cons. } & \text { State } & \text { Sig. } & \text { Cons. } \\ \text { China } & & \text { 10 Jan 89 } & \text { Mongolia } & \text { 23 Jan 86 } & \text { 28 May 86 } \\ \text { Indonesia } & \text { 3 Jul 86 } & \text { 5 Nov 86 } & \text { Philippines } & \text { 19 May 80 } & \text { 22 Sep 81 } \\ \text { Japan } & & \text { 28 Oct 88 } & \text { Tajikistan } & & \text { 11 Jul 96 } \\ \text { Korea (Rep.) } & 29 \text { Dec 81 } & \begin{array}{l}\text { 7 Apr 82 } \\ \text { 2 }\end{array} & & & \end{array}$

Joint Protocol Relating to the Application of the Vienna Convention (and the Paris Convention on Third Party Liability in the Field of Nuclear Energy)

Vienna, 21 September 1988

Entry into force: 27 April 1992

(Status as at 31 December 1996, IAEA doc. INFCIRC/402/Add.2)

State Sig.

Philippines $\quad 21$ Sep 88

Convention on Early Notification of a Nuclear Accident

Vienna, 26 September 1986

Entry into force: 27 October 1986

(Status as furnished by the IAEA Secretariat on 13 May 1997) 


$\begin{array}{llllll}\text { State } & \text { Sig. } & \text { Cons. (deposit) } & \text { State } & \text { Sig. } & \text { Cons. (deposit) } \\ \text { Afghanistan } & \text { 26 Sep 86 } & & \text { Korea (Rep.) } & & \text { 8 Jun 90 } \\ \text { Bangladesh } & & \text { 7 Jan 88 } & \text { Malaysia } & \text { 1 Sep 87 } & \text { 1 Sep 87 } \\ \text { China } & \text { 26 Sep 86 } & \text { 10 Sep 87 } & \text { Mongolia } & \text { 8 Jan 87 } & \text { 11 Jun 87 } \\ \text { India } & \text { 29 Sep 86 } & \text { 28 Jan 88 } & \text { Pakistan } & & \text { 11 Sep 89 } \\ \text { Indonesia } & \text { 26 Sep 86 } & \text { 12 Nov 93 } & \text { Philippines } & & \text { 5 May 97 } \\ \text { Iran } & \text { 26 Sep 86 } & & \text { Sri Lanka } & & \text { 11 Jan 91 } \\ \text { Japan } & \text { 6 Mar 87 } & \text { 9 Jun 87 } & \text { Thailand } & \text { 25 Sep 87 } & \text { 21 Mar 89 } \\ \text { Korea (DPR) } & \text { 29 Sep 86 } & & \text { Vietnam } & & \text { 29 Sep 87 }\end{array}$

Convention on Assistance in the Case of a Nuclear Accident or Radiological Emergency

Vienna, 26 September 1986

Entry into force: 26 february 1987

(Status as furnished by IAEA Secretariat on 13 May 1997)

$\begin{array}{llllll}\begin{array}{l}\text { State } \\ \text { Afghanistan }\end{array} & \text { Sig. } & \text { Cons. (deposit) } & \text { State } & \text { Sig. } & \begin{array}{l}\text { Cons. (deposit) } \\ \text { 26 Sep 86 }\end{array} \\ \text { Bangladesh } & & \text { 7 Jan 88 } & \text { Korea (Rep.) } & & \text { Malaysia } \\ \text { China } & \text { 26 Sep 86 } & \text { 10 Sep 87 } & \text { Mongolia } & \text { 8 Jan 87 } & \text { 1 Sep 87 } \\ \text { India } & \text { 29 Sep 86 } & \text { 28 Jan 88 } & \text { Pakistan } & & \text { 11 Sep 89 } \\ \text { Indonesia } & \text { 26 Sep 86 } & \text { 12 Nov 93 } & \text { Philippines } & & \text { 5 May 97 } \\ \text { Iran } & \text { 26 Sep 86 } & & \text { Sri Lanka } & & \text { 11 Jan 91 } \\ \text { Japan } & \text { 6 Mar 87 } & \text { 9 Jun 87 } & \text { Thailand } & \text { 25 Sep 87 } & \text { 21 Mar 89 } \\ \text { Korea (DPR) } & \text { 29 Sep 86 } & & \text { Vietnam } & & \text { 29 Sep 87 }\end{array}$

\section{OUTER SPACE}

Treaty on Principles Governing the Activities of the States in the Exploration and Use of Outer Space, Including the Moon and Other Celestial Bodies

London, Moscow, Washington, 27 January 1967

Entry into force: 10 October 1967

(Status as included in A/46/604 and TIF)

\begin{tabular}{|c|c|c|c|c|c|}
\hline State & Sig. & Cons. & State & Sig. & Cons. \\
\hline Afghanistan & yes & yes & Myanmar & yes & yes \\
\hline Bangladesh & ” & & Nepal & ” & n \\
\hline China & $"$ & & Pakistan & $"$ & " \\
\hline India & ” & ” & Papua & & \\
\hline Indonesia & ” & & New Guinea & & " \\
\hline Iran & $"$ & & Philippines & n & $"$ \\
\hline Japan & ” & » & Singapore & & ” \\
\hline Korea (Rep.) & ” & ” & Sri Lanka & n & ” \\
\hline Laos & $"$ & $n$ & Thailand & " & ” \\
\hline Malaysia & $n$ & & Vietnam & & " \\
\hline Mongolia & ” & ” & & & \\
\hline
\end{tabular}

Convention on Registration of Objects Launched into Outer Space New York, 12 November 1974

Entry into force: 15 September 1976 


$\begin{array}{llllll}\text { State } & \text { Sig. } & \text { Cons. } & \text { State } & \text { Sig. } & \text { Cons. } \\ \text { China } & & 12 \text { Dec } 88 & \text { Mongolia } & 30 \text { Oct } 75 & 10 \text { Apr } 85 \\ \text { India } & & 18 \text { Jan } 82 & \text { Pakistan } & 1 \text { Dec } 75 & \text { 27 Feb } 86 \\ \text { Iran } & 27 \text { May } 95 & & \text { Seychelles } & & \text { 28 Dec } 77 \\ \text { Japan } & & \text { 20 Jun } 83 & \text { Singapore } & \text { 31 Aug 76 } & \\ \text { Korea (Rep.) } & & \text { 14 Oct } 81 & & & \end{array}$

\section{Agreement governing the Activities of States on the Moon and other Celestial Bodies}

New York, 5 December 1979

Entry into force: 11 July 1984

$\begin{array}{llllll}\text { State } & \text { Sig. } & \text { Cons. } & \text { State } & \text { Sig. } & \text { Cons. } \\ \text { India } & \text { 18 Jan } 92 & & \text { Philippines } & \text { 23 Apr 80 } & \text { 26 May } 81 \\ \text { Pakistan } & & \text { 27 Feb 86 } & & & \end{array}$

\section{PRIVILEGES AND IMMUNITIES}

\section{Convention on the Privileges and Immunities of the United Nations}

New York, 13 February 1946

Entry into force: for each state on the date of deposit of its instrument of accession

$\begin{array}{llll}\text { State } & \text { Cons. } & \text { State } & \text { Cons. } \\ \text { Afghanistan } & 5 \text { Sep } 47 & \text { Mongolia } & \text { 31 May 62 } \\ \text { Bangladesh } & 13 \text { Jan 78 } & \text { Myanmar } & \text { 25 Jan 55 } \\ \text { Cambodia } & 6 \text { Nov 63 } & \text { Nepal } & \text { 28 Sep 65 } \\ \text { China } & 11 \text { Sep 79 } & \text { Pakistan } & \text { 8 Jan } 48 \\ \text { India } & 13 \text { May } 48 & \text { Papua } & \\ \text { Indonesia } & 8 \text { Mar 72 } & \text { New Guinea } & 4 \text { Dec } 75 \\ \text { Iran } & 8 \text { May } 47 & \text { Philippines } & 28 \text { Oct } 47 \\ \text { Japan } & 18 \text { Apr } 63 & \text { Singapore } & 18 \text { Mar } 66 \\ \text { Korea (Rep.) } & 9 \text { Apr } 92 & \text { Thailand } & 30 \text { Mar } 56 \\ \text { Laos } & 24 \text { Nov } 56 & \text { Vietnam } & 6 \text { Apr } 88 \\ \text { Malaysia } & 28 \text { Oct } 57 & & \end{array}$

Convention on the Privileges and Immunities of the Specialized Agencies New York, 21 November 1947, UNGA Res. 179 (II)

Entry into force for each state: on date of deposit or receipt of notification

$\begin{array}{lll}\text { State } & \text { Cons. } & \text { applicable to } \\ \text { Cambodia } & \text { 15 Oct 53 } & \text { UPU } \\ & \text { 26 Sep 55 } & \text { FAO, ICAO, UNESCO, WHO, ITU, WMO } \\ \text { China } & \text { 11 Sep 79 } & \text { FAO, ICAO, UNESCO, WHO, UPU, ITU, WMO, IMO } \\ & \text { 30 Jun 81 } & \text { IMF, IBRD, IFC, IDA } \\ \text { India } & 9 \text { Nov 84 } & \text { ILO } \\ & \text { 10 Feb 49 } & \text { ILO, FAO, ICAO, UNESCO, WHO } \\ & \text { 19 Oct 49 } & \text { IMF, IBRD, UPU } \\ & 9 \text { Mar 55 } & \text { WMO } \\ & \text { 3 Jun 55 } & \text { WHO (Annex rev.), ITU } \\ & \text { 3 Jul 58 } & \text { WHO (Annex rev.) } \\ & \text { 3 Aug 61 } & \text { IFC } \\ \text { Indonesia } & \text { 12 Apr 63 } & \text { FAO (Annex rev.) } \\ & \text { 8 Mar 72 } & \text { ILO, FAO, ICAO, UNESCO, IMF, IBRD, WHO, UPU, ITU, } \\ & & \text { WMO, IMO, IFC, IDA }\end{array}$




\begin{tabular}{|c|c|c|}
\hline State & Cons. & applicable to \\
\hline Iran & 16 May 74 & $\begin{array}{l}\text { ILO, FAO, ICAO, UNESCO, IMF, IBRD, WHO, UPU, ITU, } \\
\text { WMO, IMO, IFC, IDA }\end{array}$ \\
\hline Japan & 18 Apr 63 & $\begin{array}{l}\text { ILO, FAO, ICAO, UNESCO, IMF, IBRD, WHO, UPU, ITU, } \\
\text { WMO, IMO, IFC, IDA }\end{array}$ \\
\hline Korea (Rep.) & 13 May 77 & FAO, ICAO, UNESCO, IMF, IBRD, WHO, UPU, ITU, WMO \\
\hline Laos & 9 Aug 60 & $\begin{array}{l}\text { ILO, FAO, ICAO, UNESCO, IMF, IBRD, WHO, UPU, ITU, } \\
\text { WMO, IMO, IFC }\end{array}$ \\
\hline Malaysia & $\begin{array}{l}29 \text { Mar } 62 \\
23 \text { Nov } 62\end{array}$ & $\begin{array}{l}\text { ILO, FAO, ICAO, UNESCO, WHO, UPU, ITU, WMO } \\
\text { WHO (Annex rev.) }\end{array}$ \\
\hline Maldives & 26 May 69 & WHO, UPU, ITU, IMO \\
\hline Mongolia & $\begin{array}{l}3 \text { Mar } 70 \\
20 \text { Sep } 74\end{array}$ & $\begin{array}{l}\text { ILO, UNESCO, WHO, UPU, ITU, WMO } \\
\text { FAO }\end{array}$ \\
\hline Nepal & $\begin{array}{l}23 \text { Feb } 54 \\
28 \text { Sep } 65\end{array}$ & $\begin{array}{l}\text { WHO } \\
\text { FAO, ICAO, UNESCO, IMF, IBRD, UPU, ITU }\end{array}$ \\
\hline Pakistan & $\begin{array}{l}23 \text { Jul } 51 \\
7 \text { Nov } 51 \\
15 \text { Sep } 61 \\
13 \text { Mar } 62 \\
17 \text { Jul } 62\end{array}$ & $\begin{array}{l}\text { IBRD } \\
\text { IMF } \\
\text { ILO, ICAO, UNESCO, WHO, UPU, ITU, WMO } \\
\text { FAO, IMO } \\
\text { IFC, IDA }\end{array}$ \\
\hline Philippines & $\begin{array}{l}20 \text { Mar } 50 \\
21 \text { May } 58 \\
12 \text { Mar } 59 \\
13 \text { Jan } 61\end{array}$ & $\begin{array}{l}\text { ILO, FAO, ICAO, UNESCO, IMF, IBRD, WHO } \\
\text { WMO } \\
\text { WHO (Annex rev.) } \\
\text { IFC }\end{array}$ \\
\hline Singapore & 18 Mar 66 & ILO, FAO, ICAO, UNESCO, WHO, UPU, ITU, WMO \\
\hline Thailand & $\begin{array}{l}30 \text { Mar } 56 \\
19 \text { Jun } 61 \\
28 \text { Apr } 65 \\
21 \text { Mar } 66\end{array}$ & $\begin{array}{l}\text { FAO, ICAO } \\
\text { ILO, FAO, UNESCO, IMF, IBRD, WHO, ITU, WMO, IFC } \\
\text { UPU } \\
\text { FAO }\end{array}$ \\
\hline
\end{tabular}

Vienna Convention on Diplomatic Relations

Vienna, 18 April 1961

Entry into force: 24 April 1964

\begin{tabular}{|c|c|c|c|c|c|}
\hline State & Sig. & Cons. & State & Sig. & Cons \\
\hline Afghanistan & & 6 Oct 65 & Mongolia & & 5 Jan 67 \\
\hline Bangladesh & & $13 \operatorname{Jan} 78$ & Myanmar & & 7 Mar 80 \\
\hline Bhutan & & 7 Dec 72 & Nepal & & 28 Sep 65 \\
\hline Cambodia & & 31 Aug 65 & Pakistan & 29 Mar 62 & 29 Mar 62 \\
\hline China & & 25 Nov 75 & Papua & & \\
\hline India & & 15 Oct 65 & New Guinea & & $4 \operatorname{Dec} 75$ \\
\hline Indonesia & & 4 Jun 82 & Philippines & 20 Oct 61 & 15 Nov 65 \\
\hline Iran & 27 May 61 & 3 Feb 65 & Seychelles & & 29 May 79 \\
\hline Japan & 26 Mar 62 & 8 Jun 64 & Sri Lanka & 18 Apr 61 & 2 Jun 78 \\
\hline Kazakhstan & & $5 \operatorname{Jan} 94$ & Tajikistan & & 6 May 1996 \\
\hline Korea (DPR) & & 29 Oct 80 & Thailand & 30. Oct 61 & $23 \operatorname{Jan} 85$ \\
\hline Korea (Rep.) & 28 Mar 62 & $28 \operatorname{Dec} 70$ & Turkmenistan & & 25 Sep 96 \\
\hline Kyrgyzstan & & 7 Oct 94 & Uzbekistan & & $2 \operatorname{Mar} 92$ \\
\hline Laos & & $3 \operatorname{Dec} 62$ & Vietnam & & 26 Aug 80 \\
\hline Malaysia & & 9 Nov 65 & & & \\
\hline
\end{tabular}

Optional Protocol to the Vienna Convention on Diplomatic Relations concerning the Compulsory Settlement of Disputes

Vienna, 18 April 1961

Entry into force: 24 April 1964 


$\begin{array}{llllll}\text { State } & \text { Sig. } & \text { Cons. } & \text { State } & \text { Sig. } & \text { Cons. } \\ \text { Cambodia } & & \text { 31 Aug 65 } & \text { Malaysia } & & \text { 9 Nov 65 } \\ \text { India } & & \text { 15 Oct 65 } & \text { Nepal } & & \text { 28 Sep 65 } \\ \text { Iran } & \text { 27 May 61 } & \text { 3 Feb 65 } & \text { Pakistan } & & \text { 29 Mar 76 } \\ \text { Japan } & \text { 26 Mar 62 } & \text { 8 Jun 64 } & \text { Philippines } & \text { 20 Oct 61 } & \text { 15 Nov 65 } \\ \text { Korea (Rep.) } & \text { 30 Mar 62 } & \text { 25 Jan 77 } & \text { Sri Lanka } & & \text { 31 Jul 78 } \\ \text { Laos } & & \text { 3 Dec 62 } & & & \end{array}$

\section{Vienna Convention on Consular Relations \\ Vienna, 24 April 1963 \\ Entry into force: 19 March 1967}

\begin{tabular}{|c|c|c|c|c|c|}
\hline State & Sig. & Cons. & State & Sig. & Cons. \\
\hline Bangladesh & & $13 \operatorname{Jan} 78$ & Maldives & & $21 \operatorname{Jan} 91$ \\
\hline Bhutan & & $28 \mathrm{Jul} 81$ & Malaysia & & 1 Oct 91 \\
\hline China & & 2 Jul 79 & Mongolia & & 14 Mar 89 \\
\hline India & & 28 Nov 77 & Nepal & & $28 \operatorname{Sep} 65$ \\
\hline Indonesia & & 4 Jun 82 & Pakistan & & 14 Apr 69 \\
\hline Iran & 24 Apr 63 & 5 Jun 75 & Papua & & \\
\hline Japan & & 3 Oct 83 & New Guinea & & $4 \operatorname{Dec} 75$ \\
\hline Kazakhstan & & 5 Jan 94 & Philippines & 24 Apr 63 & 15 Nov 65 \\
\hline Korea (DPR) & & 8 Aug 84 & Tajikistan & & 6 May 96 \\
\hline Korea (Rep.) & & 7 Mar 77 & Turkmenistan & & 25 Sep 96 \\
\hline Kyrgyzstan & & 7 Oct 94 & Uzbekistan & & 2 Mar 92 \\
\hline Laos & & 9 Aug 73 & Vietnam & & $8 \operatorname{Sep} 92$ \\
\hline
\end{tabular}

Optional Protocol to the Vienna Convention on Consular Relations concerning the Compulsory Settlement of Disputes

Vienna, 24 April 1963

Entry into force: 19 March 1967

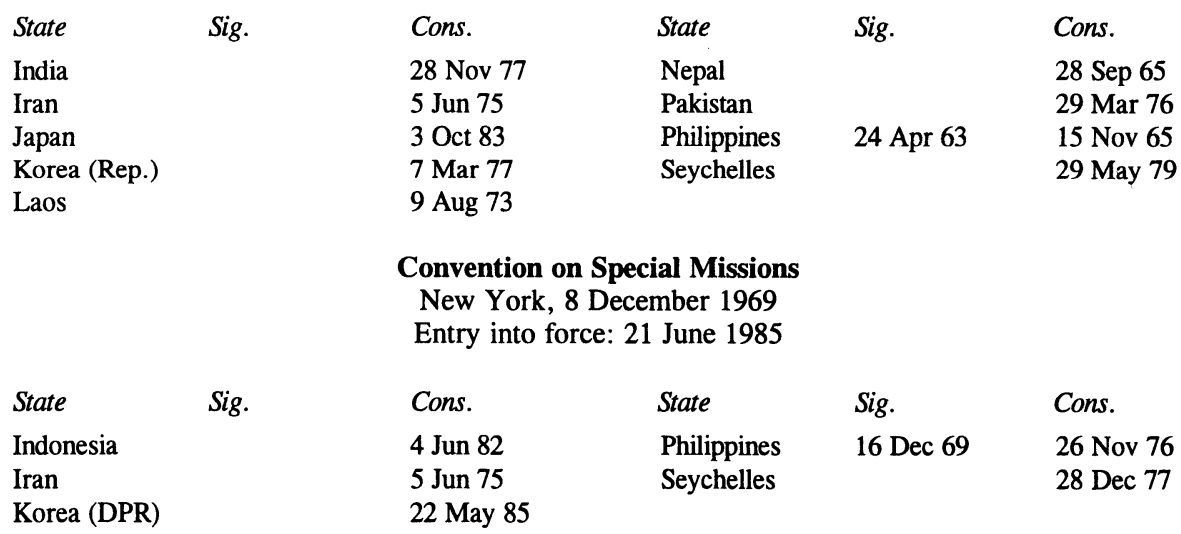

Optional Protocol to the Convention on Special Missions concerning the Compulsory Settlement of Disputes

UNGA, New York, 8 December 1969

Entry into force: 21 June 1985

State

Sig. $\quad$ Cons.

State

Sig.

Cons.

Iran

5 Jun 75

Philippines

$16 \operatorname{Dec} 69$

26 Nov 76 


\section{REFUGEES}

\section{Convention relating to the Status of Refugees}

Geneva, 28 July 1951

Entry into force: 22 April 1954

State

Cambodia

China

Iran

Japan

Korea (Rep.)
Cons.

15 Oct 92

24 Sep 82

$28 \mathrm{Jul} 76$

3 Oct 81

3 Dec 92
State

Kyrgyzstan

Papua New Guinea

Philippines

Tajikistan
Cons.

8 Oct 96

17 Jul 86

22 Jul 81

7 Dec 93

Protocol relating to the Status of Refugees

New York, 31 January 1967

Entry into force: 4 October 1967

State

Cambodia

China

Iran

Japan

Korea (Rep.)
Cons.

15 Oct 92

24 Sep 82

$28 \mathrm{Jul} 76$

1 Jan 82

3 Dec 92
State

Kyrgyzstan

Papua New Guinea

Philippines

Tajikistan
Cons.

8 Oct 96

17 July 86

22 Jul 81

7 Dec 93

\section{ROAD TRAFFIC AND TRANSPORT}

Convention on Road Traffic

Vienna, 8 November 1968

Entry into force: 21 May 1977

\section{State \\ Indonesia \\ Iran \\ Kazakhstan \\ Korea (Rep.) \\ Kyrgyzstan \\ Pakistan}

Sig.

8 Nov 68

8 Nov 68

29 Dec 69

4 Apr 94

22 Mar 94

19 Mar 86
State

Philippines

Tajikistan

Thailand

Turkmenistan

Uzbekistan
Sig.

8 Nov 68

8 Nov 68

Cons.

27 Dec 73

9 Mar 94

14 Jan 93

17 Jan 95

\section{Convention on Road Signs and Signals}

Vienna, 8 November 1968

Entry into force: 6 June 1978

\begin{tabular}{|c|c|c|c|c|c|}
\hline State & Sig. & Cons. & State & Sig. & Cons. \\
\hline India & & 10 Mar 80 & Pakistan & & $14 \operatorname{Jan} 80$ \\
\hline Indonesia & 8 Nov 68 & & Philippines & 8 Nov 68 & $27 \operatorname{Dec} 73$ \\
\hline Iran & 8 Nov 68 & 21 May 76 & Tajikistan & & 9 Mar 94 \\
\hline Kazakhstan & & 4 Apr 94 & Thailand & 8 Nov 68 & \\
\hline Korea (Rep.) & $29 \operatorname{Dec} 69$ & & Turkmenistan & & 14 Jan 93 \\
\hline Kyrgyzstan & & 22 Mar 94 & Uzbekistan & & $17 \operatorname{Jan} 95$ \\
\hline
\end{tabular}


SEA

Convention on the Territorial Sea and the Contiguous Zone Geneva, 29 April 1958

Entry into force: 10 September 1964

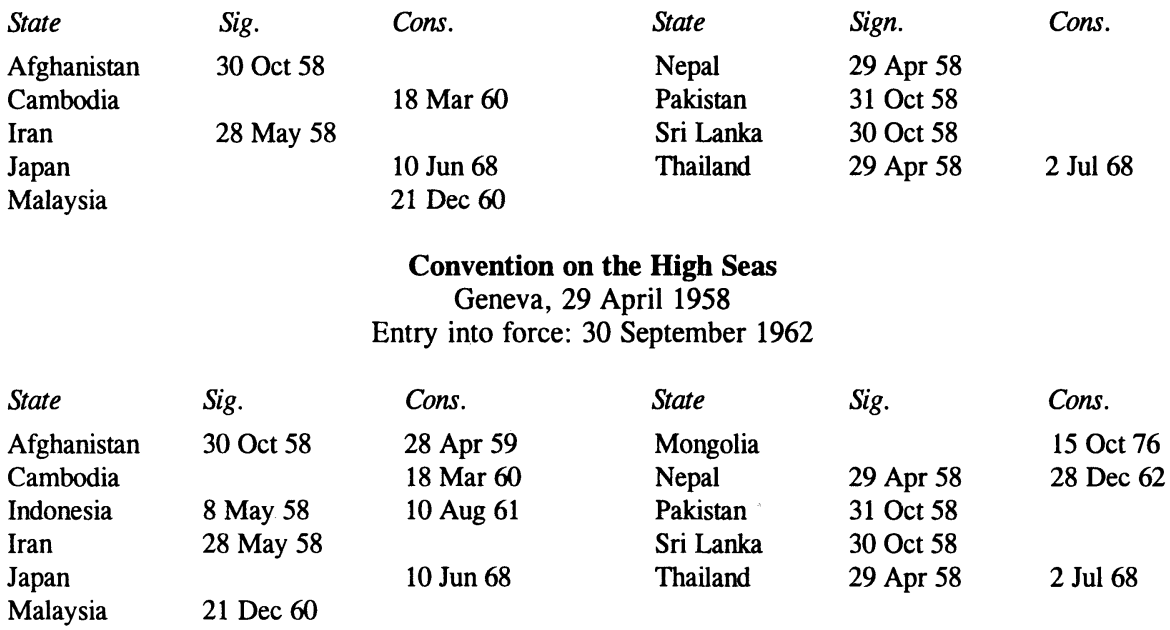

Convention on Fishing and Conservation of the Living Resources of the High Seas Geneva, 29 April 1958

Entry into force: 20 March 1966

\begin{tabular}{|c|c|c|c|c|c|}
\hline State & Sig. & Cons. & State & Sig. & Cons. \\
\hline Afghanistan & 30 Oct 58 & & Nepal & 29 Apr 58 & \\
\hline Cambodia & & $18 \operatorname{Mar} 60$ & Pakistan & 31 Oct 58 & \\
\hline Indonesia & 8 May 58 & & Sri Lanka & 30 Oct 58 & \\
\hline Iran & 28 May 58 & & Thailand & 29 Apr 58 & 2 Jul 68 \\
\hline Malaysia & & $21 \mathrm{Dec} 60$ & & & \\
\hline \multicolumn{6}{|c|}{$\begin{array}{c}\text { Convention on the Continental Shelf } \\
\text { Geneva, } 29 \text { April } 1958 \\
\text { Entry into force: } 10 \text { June } 1964\end{array}$} \\
\hline State & Sig. & Cons. & State & Sig. & Cons. \\
\hline $\begin{array}{l}\text { Afghanistan } \\
\text { Cambodia }\end{array}$ & 30 Oct 58 & $18 \operatorname{Mar} 60$ & $\begin{array}{l}\text { Nepal } \\
\text { Pakistan }\end{array}$ & $\begin{array}{l}29 \text { Apr } 58 \\
31 \text { Oct } 58\end{array}$ & \\
\hline Indonesia & 8 May 58 & & Sri Lanka & 30 Oct 58 & \\
\hline Iran & 28 May 58 & & Thailand & 29 Apr 58 & 2 Jul 68 \\
\hline Malaysia & & $21 \operatorname{Dec} 60$ & & & \\
\hline
\end{tabular}




\section{Optional Protocol of Signature concerning the Compulsory Settlement of Disputes} Geneva, 29 April 1958

Entry into force: 30 September 1962

$\begin{array}{llllll}\text { State } & \text { Sig. } & \text { Cons. } & \text { State } & \text { Sig. } & \text { Cons. } \\ \text { Cambodia } & \text { 22 Jan 70 } & & \text { Nepal } & & \text { 29 Apr 58 } \\ \text { Indonesia } & \text { 8 May 58 } & & \text { Pakistan } & & \text { 6 Nov } 58 \\ \text { Malaysia } & & \text { 1 May 61 } & \text { Sri Lanka } & & \text { 30 Oct } 58\end{array}$

\section{United Nations Convention on the Law of the Sea \\ Montego Bay, 10 December 1982 \\ Entry into force: 16 November 1994}

\begin{tabular}{|c|c|c|c|c|c|}
\hline State & Sig. & Cons. & State & Sig. & Cons. \\
\hline Afghanistan & $18 \operatorname{Mar} 83$ & & Maldives & $10 \operatorname{Dec} 82$ & \\
\hline Bangladesh & $10 \operatorname{Dec} 82$ & & Mongolia & 10 Dec 82 & 13 Aug 96 \\
\hline Bhutan & $10 \mathrm{Dec} 82$ & & Myanmar & 10 Dec 82 & 21 May 96 \\
\hline Brunei & 5 Dec 84 & 5 Nov 96 & Nepal & 10 Dec 82 & \\
\hline Cambodia & $1 \mathrm{Jul} 83$ & & Pakistan & 10 Dec 82 & \\
\hline China & $10 \operatorname{Dec} 82$ & 7 June 96 & Papua & & \\
\hline India & 10 Dec 82 & 29 Jun 95 & New Guinea & 10 Dec 82 & \\
\hline Indonesia & $10 \operatorname{Dec} 82$ & 3 Feb 86 & Philippines & $10 \operatorname{Dec} 82$ & 8 May 84 \\
\hline Iran & 10 Dec 82 & & Seychelles & 10 Dec 82 & 16 Sep 91 \\
\hline Japan & 7 Feb 83 & 20 Jun 96 & Singapore & 10 Dec 82 & 17 Nov 94 \\
\hline Korea (DPR) & 10 Dec 82 & & Sri Lanka & 10 Dec 82 & $19 \mathrm{Jul} 94$ \\
\hline Korea (Rep.) & 14 Mar 83 & $29 \mathrm{Jan} 96$ & Thailand & 10 Dec 82 & \\
\hline Laos & 10 Dec 82 & & Vietnam & 10 Dec 82 & $25 \mathrm{Jul} 94$ \\
\hline Malaysia & $10 \mathrm{Dec} 82$ & 14 Oct 96 & & & \\
\hline
\end{tabular}

\section{Agreement relating to the Implementation of Part XI of the United Nations}

Convention on the Law of the Sea of 10 December 1982

New York, 28 July 1994

Entry into force: 28 July 1996

(all countries listed below agreed to provisional application as from 16 November 1994)

\begin{tabular}{|c|c|c|c|c|c|}
\hline State & Sig. & Cons. & State & Sig. & Cons. \\
\hline Afghanistan & & & Maldives & 10 Oct 94 & \\
\hline Bangladesh & & & Mongolia & 17 Aug 94 & 13 Aug 96 \\
\hline Bhutan & & & Myanmar & & 21 May 96 \\
\hline Brunei & & 5 Nov 96 & Nepal & & \\
\hline Cambodia & & & Pakistan & 10 Aug 94 & \\
\hline China & 29 Jul 94 & 7 Jun 96 & Papua & & \\
\hline India & $29 \mathrm{Jul} 94$ & 29 Jun 95 & New Guinea & & \\
\hline Indonesia & $29 \mathrm{Jul} 94$ & & Philippines & 15 Nov 94 & \\
\hline Japan & 29 Jul 94 & 20 Jun 96 & Singapore & & 17 Nov 94 \\
\hline Korea (Rep.) & 7 Nov 94 & 29 Jan 96 & Sri Lanka & 29 Jul 94 & $28 \mathrm{Jul} 95$ \\
\hline Laos & 27 Oct 94 & & Vietnam & & \\
\hline Malaysia & 2 Aug 94 & 14 Oct 96 & & & \\
\hline
\end{tabular}




\section{SEA TRAFFIC AND TRANSPORT}

\section{Convention Regarding the Measurement and Registration of Vessels Employed in Inland Navigation \\ Bangkok, 22 June 1956 \\ Entry into force: -}

$\begin{array}{llll}\text { State } & \text { Sig. } & \text { State } & \text { Sig. } \\ \text { Cambodia } & \text { 22 Jun 56 } 56 & \text { Laos } & \text { 22 Jun 56 } \\ \text { China } & \text { 22 Jun 56 } & \text { Thailand } & \text { 22 Jun 56 } \\ \text { Indonesia } & \text { 22 Jun 56 } & & \end{array}$

International Convention for the Safety of Life at Sea London, 17 July 1960

Entry into force: 26 May 1965

(Status as included in IMO Doc. J/6233, as at 31 December 1995)

$\begin{array}{llllll}\text { State } & \text { Cons. } & \text { E.i.f. } & \text { State } & \text { Cons. } & \text { E.i.f. } \\ \text { Bangladesh } & \text { 10 May 78 } & \text { 10 Aug 78 } & \text { Maldives } & \text { 29 Jan 68 } & \text { 29 Apr 68 } \\ \text { Cambodia } & \text { 24 Nov 70 } & \text { 24 Feb 71 } & \text { Myanmar } & \text { 12 Jul 65 } & \text { 12 Oct 68 } \\ \text { China } & \text { 5 Oct 73 } & \text { 5 Jan 74 } & \text { Pakistan } & \text { 24 Feb 66 } & \text { 24 May 66 } \\ \text { India } & \text { 28 Feb 66 } & \text { 28 May 66 } & \text { Papua New } & & \\ \text { Indonesia } & \text { 26 Oct 66 } & \text { 26 Jan 67 } & \text { Guinea } & \text { 18 May 76 } & \text { 18 Aug 76 } \\ \text { Iran } & \text { 31 May 66 } & \text { 31 Aug 66 } & \text { Philippines } & \text { 11 Aug 65 } & \text { 11 Nov 65 } \\ \text { Japan } & \text { 23 Apr 63 } & \text { 26 May 65 } & \text { Singapore } & \text { 12 Feb 69 } & \text { 12 May 69 } \\ \text { Korea (Rep.) } & \text { 21 May 65 } & \text { 26 May 65 } & \text { Sri Lanka } & \text { 10 May 74 } & \text { 10 Aug 74 } \\ \text { Malaysia } & \text { 16 Aug 65 } & \text { 16 Nov 65 } & \text { Vietnam } & \text { 8 Jan 62 } & \text { 26 May 65 }\end{array}$

Convention on Facilitation of International Maritime Traffic

London, 9 April 1965 (as amended)

Entry into force: 5 March 1967

(Status as included in IMO doc. J/6233, as at 31 December 1995)

$\begin{array}{llllll}\text { State } & \text { Cons. } & \text { E.i.f. } & \text { State } & \text { Cons. } & \text { E.i.f. } \\ \text { China } & \text { 16 Jan 95 } & \text { 17 Mar 95 } & \text { Korea (DPR) } & \text { 24 Apr 92 } & \text { 23 Jun 92 } \\ \text { India } & \text { 25 May 76 } & \text { 24 Jul 76 } & \text { Singapore } & \text { 3 Apr 67 } & \text { 2 Jun 67 } \\ \text { Iran } & \text { 27 Mar 95 } & \text { 26 May 95 } & \text { Thailand } & \text { 28 Nov 91 } & \text { 27 Jan 92 }\end{array}$

International Convention on Load Lines, 1966

London, 5 April 1966

Entry into force: 21 July 1968

(Status as included in IMO doc. J/6233, as at 31 December 1995) 


\begin{tabular}{|c|c|c|c|c|c|}
\hline State & Cons. & E.i.f. & State & Cons. & E.i.f. \\
\hline Bangladesh & 10 May 78 & 10 Aug 78 & Malaysia & $12 \operatorname{Jan} 71$ & 12 Apr 71 \\
\hline Brunei & $6 \operatorname{Mar} 87$ & 6 Jun 87 & Amendm. 79: & $4 \operatorname{Mar} 83$ & \\
\hline Cambodia & 28 Nov 94 & 28 Feb 95 & Maldives & $29 \mathrm{Jan} 68$ & $21 \mathrm{Jul} 68$ \\
\hline China & 5 Oct 73 & $5 \mathrm{Jan} 74$ & Amendm. 79: & 11 Mar 80 & \\
\hline Amendm. 71: & 1 Aug 80 & & Amendm. 83: & 25 Apr 84 & \\
\hline Amendm. 75: & 1 Aug 80 & & Myanmar & 11 Nov 87 & 11 Feb 88 \\
\hline Amendm. 79: & 1 Aug 80 & & Amendm. 71: & 11 Nov 87 & \\
\hline Amendm. 83: & 9 Sep 86 & & Pakistan & 5 Dec 68 & 5 Mar 69 \\
\hline India & 19 Apr 68 & 21 Jul 68 & Papua New & & \\
\hline Amendm. 75: & 31 Jan 77 & & Guinea & 18 May 76 & 18 Aug 76 \\
\hline Amendm. 79: & 23 May 88 & & Philippines & 4 Mar 69 & 4 Jun 69 \\
\hline Indonesia & 17 Jan 77 & 17 Jan 77 & Amendm. 71: & 1 Feb 73 & \\
\hline Iran & 5 Oct 73 & 5 Jan 74 & Singapore & 21 Sep 71 & $21 \operatorname{Dec} 71$ \\
\hline Japan & 15 May 68 & 15 Aug 68 & Sri Lanka & 10 May 74 & 10 Aug 74 \\
\hline Kazakhstan & 7 Mar 94 & 7 Jun 94 & Amendm. 79: & 27 Nov 80 & \\
\hline Korea (DPR) & 18 Oct 89 & 18 Jan 90 & Thailand & 30 Dec 92 & 30 Mar 93 \\
\hline Korea (Rep.) & $10 \mathrm{Jul} 69$ & 10 Oct 69 & Vietnam & $18 \operatorname{Dec} 90$ & 18 Mar 91 \\
\hline
\end{tabular}

Protocol Relating to the International Convention on Load Lines 1966 London, 11 November 1988

Entry into force: -

(Status as included in IMO doc. J/6233, as at 31 December 1995)

$\begin{array}{llllll}\text { State } & \text { Cons. } & \text { E.i.f. } & \text { State } & \text { Cons. } & \text { E.i.f. } \\ \text { China } & 3 \text { Feb } 95 & & \text { Korea (Rep.) } & 14 \text { Nov } 94 & \end{array}$

International Convention on Tonnage Measurement of Ships London, 23 June 1969

Entry into force: 18 July 1982

(Status as included in IMO doc. J/6233, as at 31 December 1995)

$\begin{array}{llllll}\text { State } & \text { Cons. } & \text { E.i.f. } & \text { State } & \text { Cons. } & \text { E.i.f. } \\ \text { Bangladesh } & \text { 6 Nov 81 } & \text { 18 Jul 82 } & \text { Malaysia } & \text { 24 Apr 84 } & \text { 24 Jul 84 } \\ \text { Brunei } & \text { 23 Oct 86 } & \text { 23 Jan 87 } & \text { Maldives } & \text { 2 Jun 83 } & \text { 2 Sep 83 } \\ \text { Cambodia } & \text { 28 Nov 94 } & \text { 28 Feb 95 } & \text { Myanmar } & \text { 4 May 88 } & \text { 4 Aug 88 } \\ \text { China } & \text { 8 Apr 80 } & \text { 18 Jul 82 } & \text { Pakistan } & \text { 17 Oct 94 } & \text { 17 Jan 95 } \\ \text { India } & \text { 26 May 77 } & \text { 18 Jul 82 } & \text { Papua New } & & \\ \text { Indonesia } & \text { 14 Mar 89 } & \text { 14 Jun 89 } & \text { Guinea } & \text { 25 Oct 93 } & \text { 25 Jan 94 } \\ \text { Iran } & \text { 28 Dec 73 } & \text { 18 Jul 82 } & \text { Philippines } & \text { 6 Sep 78 } & \text { 18 Jul 82 } \\ \text { Japan } & \text { 17 Jul 80 } & \text { 18 Jul 82 } & \text { Singapore } & \text { 6 Jun 85 } & \text { 6 Sep 85 } \\ \text { Kazakhstan } & \text { 7 Mar 94 } & \text { 7 Jun 94 } & \text { Sri Lanka } & \text { 11 Mar 92 } & \text { 11 Jun 92 } \\ \text { Korea (DPR) } & \text { 18 Oct 89 } & \text { 18 Jan } 90 & \text { Vietnam } & \text { 18 Dec 90 } & \text { 18 Mar 91 } \\ \text { Korea (Rep.) } & \text { 18 Jan } 80 & \text { 18 Jul 82 } & & & \end{array}$




\section{Special Trade Passenger Ships Agreement \\ London, 6 October 1971 \\ Entry into force: 2 January 1974}

(Status as included in IMO Doc. J/6233, as at 31 December 1995)

$\begin{array}{llllll}\text { State } & \text { Cons. } & \text { E.i.f. } & \text { State } & \text { Cons. } & \text { E.i.f. } \\ \text { Bangladesh } & \text { 10 Aug 78 } & \text { 10 Nov 78 } & \text { Philippines } & \text { 2 Jul 73 } & \text { 2 Jan 74 } \\ \text { India } & \text { 1 Sep 76 } & \text { 1 Dec 76 } & \text { Sri Lanka } & \text { 10 Dec 81 } & \text { 10 Mar 82 } \\ \text { Indonesia } & \text { 13 Apr 73 } & \text { 2 Jan 74 } & & & \end{array}$

\section{Protocol on Space requirements for Special Trade Passenger Ships}

London, 13 July 1973

Entry into force: 2 June 1977

(Status as included in IMO Doc. 6233, as at 31 December 1996)

$\begin{array}{llllll}\text { State } & \text { Cons. } & \text { E.i.f. } & \text { State } & \text { Cons. } & \text { E.i.f. } \\ \text { Bangladesh } & 10 \text { Nov 78 } & \text { 10 Feb 78 } & \text { Indonesia } & 10 \text { Oct 79 } & \text { 10 Jan 80 } \\ \text { India } & 1 \text { Dec 76 } & \text { 2 Jun 77 } & \text { Sri Lanka } & \text { 10 Mar 82 } & \text { 10 Jun 82 }\end{array}$

Convention on the International Regulations for Preventing Collisions at Sea, as amended London, 20 October 1972

Entry into force: 15 July 1977

(Status as included in IMO doc. J/6233, as at 31 December 1995)

\begin{tabular}{|c|c|c|c|c|c|}
\hline State & Cons. & E.i.f. & State & Cons. & E.i.f. \\
\hline Bangladesh & 10 May 78 & 10 May 78 & & & \\
\hline Brunei & 5 Feb 87 & 5 Feb 87 & Korea (Rep.) & $29 \mathrm{Jul} 77$ & 29 Jul 77 \\
\hline Cambodia & 28 Nov 94 & 28 Nov 94 & Malaysia & $23 \operatorname{Dec} 80$ & $23 \operatorname{Dec} 80$ \\
\hline China & 7 Jan 80 & 7 Jan 80 & Maldives & $14 \operatorname{Jan} 81$ & $14 \operatorname{Jan} 81$ \\
\hline Hong Kong & 30 Oct 74 & 15 Jul 77 & Myanmar & 11 Nov 87 & 11 Nov 87 \\
\hline (by decl. UK) & & & Pakistan & $14 \operatorname{Dec} 77$ & $14 \operatorname{Dec} 77$ \\
\hline India & 30 May 73 & 15 Jul 77 & Papua New & & \\
\hline Indonesia & 13 Nov 79 & 13 Nov 79 & Guinea & 18 May 76 & $15 \mathrm{Jul} 77$ \\
\hline Iran & 17 Jan 89 & 17 Jan 89 & Singapore & 29 Apr 77 & 15 Jul 77 \\
\hline Japan & 21 Jun 77 & 15 Jul 77 & Sri Lanka & $4 \operatorname{Jan} 78$ & $4 \operatorname{Jan} 78$ \\
\hline Kazakhstan & 7 Mar 94 & 7 Mar 94 & Thailand & 6 Aug 79 & 6 Aug 79 \\
\hline Korea (DPR) & 1 May 85 & 1 May 85 & Vietnam & $18 \operatorname{Dec} 90$ & $18 \operatorname{Dec} 90$ \\
\hline
\end{tabular}

International Convention for Safe Containers, as amended

Geneva, 2 December 1972

Entry into force: 6 September 1977

(Status as included in IMO doc. J/6233, as at 31 December 1995)

$\begin{array}{llllll}\text { State } & \text { Cons. } & \text { E.i.f. } & \text { State } & \text { Cons. } & \text { E.i.f. } \\ \text { Afghanistan } & \text { 24 Jun 87 } & \text { 24 Jun 88 } & \text { Kazakhstan } & \text { 7 Mar 94 } & \text { 7 Mar 95 } \\ \text { China } & \text { 23 Sep 80 } & \text { 23 Sep 81 } & \text { Korea (DPR) } & \text { 18 Oct 89 } & \text { 18 Oct 90 } \\ \text { India } & \text { 27 Jan 78 } & \text { 27 Jan 79 } & \text { Korea (Rep.) } & \text { 18 Dec 78 } & \text { 18 Dec 79 } \\ \text { Indonesia } & \text { 25 Sep 89 } & \text { 25 Sep 90 } & \text { Pakistan } & \text { 10 Apr 85 } & \text { 10 Apr 86 } \\ \text { Japan } & \text { 12 Jun 78 } & \text { 12 Jun 79 } & & & \end{array}$




\section{Convention on a Code of Conduct for Liner Conferences Geneva, 6 April 1974 \\ Entry into force: 6 October 1983}

$\begin{array}{llllll}\text { State } & \text { Sig. } & \text { Cons. } & \text { State } & \text { Sig. } & \text { Cons. } \\ \text { Bangladesh } & & \text { 24 Jul 75 } & \text { Korea (Rep.) } & & \text { 11 May 79 } \\ \text { China } & & \text { 23 Sep 80 } & \text { Malaysia } & & \text { 27 Aug 82 } \\ \text { India } & \text { 27 Jun 75 } & \text { 14 Feb 78 } & \text { Pakistan } & & \text { 27 Jun 75 } \\ \text { Indonesia } & \text { 5 Feb 75 } & \text { 11 Jan 77 } & \text { Philippines } & \text { 2 Aug 74 } & \text { 2 Mar 76 } \\ \text { Iran } & \text { 7 Aug 74 } & & \text { Sri Lanka } & & \text { 30 Jun 75 }\end{array}$

International Convention for the Safety of Life at Sea, as amended London, 1 November 1974

Entry into force: 25 May 1980

(Status as included in IMO doc. J/6233, as at 31 December 1995)

$\begin{array}{llllll}\text { State } & \text { Cons. } & \text { E.i.f. } & \text { State } & \text { Cons. } & \text { E.i.f. } \\ \text { Bangladesh } & \text { 6 Nov 81 } & \text { 6 Feb 82 } & \text { Malaysia } & \text { 19 Oct 83 } & \text { 19 Jan 84 } \\ \text { Brunei } & \text { 23 Oct 86 } & \text { 23 Jan 87 } & \text { Maldives } & \text { 14 Jan 81 } & \text { 14 Apr 81 } \\ \text { Cambodia } & \text { 28 Nov 94 } & \text { 28 Feb 95 } & \text { Myanmar } & \text { 11 Noc 87 } & \text { 11 Feb 88 } \\ \text { China } & \text { 7 Jan 80 } & \text { 25 May 80 } & \text { Pakistan } & \text { 10 Apr 85 } & \text { 10 Jul 85 } \\ \text { India } & \text { 16 Jun 76 } & \text { 25 May 80 } & \text { Paupua New } & & \\ \text { Indonesia } & \text { 17 Feb 81 } & \text { 17 May 81 } & \text { Guinea } & \text { 12 Nov 80 } & \text { 12 Feb 81 } \\ \text { Iran } & \text { 17 Oct 94 } & \text { 17 Jan 95 } & \text { Philippines } & \text { 15 Dec 81 } & \text { 15 Mar 82 } \\ \text { Japan } & \text { 15 May 80 } & \text { 25 May 80 } & \text { Singapore } & \text { 16 Mar 81 } & \text { 16 Jun 81 } \\ \text { Kazakhstan } & \text { 7 Mar 94 } & \text { 7 Jun 94 } & \text { Sri Lanka } & \text { 30 Aug 83 } & \text { 30 Nov 83 } \\ \text { Korea (DPR) } & \text { 1 May 85 } & \text { 1 Aug 85 } & \text { Thailand } & \text { 18 Dec 84 } & \text { 18 Mar 85 } \\ \text { Korea (Rep.) } & \text { 31 Dec 80 } & \text { 31 Mar 81 } & \text { Vietnam } & \text { 18 Dec 90 } & \text { 18 Mar 91 }\end{array}$

UN Convention on the Carriage of Goods by Sea

Hamburg, 31 March 1978

Entry into force: 1 November 1992

$\begin{array}{llllll}\text { State } & \text { Sig. } & \text { Cons. } & \text { State } & \text { Sig. } & \text { Cons. } \\ \text { Pakistan } & \text { 8 Mar 79 } & & \text { Singapore } & \text { 31 Mar 78 } & \\ \text { Philippines } & \text { 14 Jun 78 } & & & & \end{array}$

Protocol Relating to the International Convention for the Safety of Life at Sea, as amended

London, 17 February 1978

Entry into force: 1 May 1981

(Status as included in IMO doc. J/6233, as at 31 December 1995)

$\begin{array}{llllll}\text { State } & \text { Cons. } & \text { E.i.f. } & \text { State } & \text { Cons. } & \text { E.i.f. } \\ \text { Brunei } & \text { 23 Oct 86 } & \text { 23 Jan 87 } & \text { Korea (DPR) } & \text { 1 May 85 } & \text { 1 Aug 85 } \\ \text { Cambodia } & \text { 28 Nov 94 } & \text { 28 Feb 95 } & \text { Korea (Rep.) } & \text { 2 Dec 82 } & \text { 2 Mar 83 } \\ \text { China } & \text { 17 Dec 82 } & \text { 17 Mar 83 } & \text { Malaysia } & \text { 19 Pct 83 } & \text { 19 Jan 84 } \\ \text { India } & \text { 3 Apr 86 } & \text { 3 Jul 86 } & \text { Myanmar } & \text { 11 Nov 87 } & \text { 11 Feb 88 } \\ \text { Indonesia } & \text { 23 Aug 88 } & \text { 23 Nov 88 } & \text { Pakistan } & \text { 10 Apr 85 } & \text { 10 Jul 85 } \\ \text { Japan } & \text { 15 May 80 } & \text { 1 May 81 } & \text { Singapore } & \text { 1 Jun 84 } & \text { 1 Sep 84 } \\ \text { Kazakhstan } & \text { 7 Mar 84 } & \text { 7 Jun 94 } & \text { Vietnam } & \text { 12 Oct 92 } & \text { 12 Jan 93 }\end{array}$




\section{SOCIAL MATTERS}

International Convention for the Suppression of the Circulation of and Traffic in Obscene Publications

Geneva, 12 September 1923

Entry into force: 7 August 1924

$\begin{array}{llll}\text { State } & \text { Cons. } & \text { State } & \text { Cons. } \\ \text { Afghanistan } & 10 \text { May 37 } & \text { Iran } & 28 \text { Sep 32 } \\ \text { China } & 24 \text { Feb 26 } & \text { Japan } & 13 \text { May 36 } \\ \text { India } & 11 \text { Dec 25 } & \text { Thailand } & \text { 28 Jul 24 }\end{array}$

International Convention for the Suppression of the Traffic in Women of Full Age Geneva, 11 October 1933

Entry into force: 24 August 1934

\begin{tabular}{|c|c|c|c|c|c|}
\hline State & Sig. & Cons. & State & Sig. & Cons \\
\hline $\begin{array}{l}\text { Afghanistan } \\
\text { China }\end{array}$ & 11 Oct 33 & 10 Apr 35 & Iran & & 12 Apr 35 \\
\hline
\end{tabular}

Convention for the Suppression of the Circulation of, and Traffic in, Obscene Publications Geneva, 12 September 1923, amended by Protocol, New York, 12 November 1947 Entry into force: 2 February 1950

$\begin{array}{lllc}\text { State } & \text { Cons. } & \text { State } & \text { Cons. } \\ \text { Afghanistan } & 12 \text { Nov } 47 & \text { Malaysia } & 21 \text { Aug } 58 \\ \text { Cambodia } & 30 \text { Mar } 59 & \text { Myanmar } & 13 \text { May } 49 \\ \text { China } & 12 \text { Nov } 47 & \text { Pakistan } & 12 \text { Nov } 47 \\ \text { India } & 12 \text { Nov } 47 & \text { Sri Lanka } & 15 \text { Apr } 58\end{array}$

Convention for the Suppression of the Traffic in Women and Children

Geneva, 30 September 1921, amended by Protocol, New York, 12 November 1947

Entry into force: 24 April 1950

$\begin{array}{llll}\text { State } & \text { Cons. } & \text { State } & \text { Cons. } \\ \text { Afghanistan } & 12 \text { Nov } 47 & \text { Pakistan } & 12 \text { Nov } 47 \\ \text { China } & 12 \text { Nov } 47 & \text { Philippines } & 30 \text { Sep } 54 \\ \text { India } & 12 \text { Nov } 47 & \text { Singapore } & 26 \text { Oct } 66 \\ \text { Myanmar } & 13 \text { May } 49 & & \end{array}$

Convention for the Suppression of the Traffic in Women of Full Age

Geneva, 11 October 1933, amended by Protocol, New York, 12 November 1949

Entry into force: 24 April 1950

State

Afghanistan

Philippines
Cons.

12 Nov 47

30 Sep 54
State

Cons

Singapore

26 Oct 66 
International Agreement for the Suppression of the White Slave Traffic

Paris, 18 May 1904, amended by Protocol, New York, 4 May 1949

Entry into force: 21 June 1951

$\begin{array}{llll}\text { State } & \text { Cons. } & \text { State } & \text { Consent } \\ \text { China } & 4 \text { May } 49 & \text { Pakistan } & \text { 16 Jun } 52 \\ \text { India } & 28 \text { Dec } 49 & \text { Singapore } & \text { 7 Jun } 66 \\ \text { Iran } & 30 \text { Dec } 59 & \text { Sri Lanka } & \text { 14 Jul } 49\end{array}$

International Convention for the Suppression of the White Slave Traffic Paris, 4 May 1910, amended by Protocol, New York 1949 Entry into force: 14 August 1951

$\begin{array}{llll}\text { State } & \text { Cons. } & \text { State } & \text { Cons. } \\ \text { China } & 4 \text { May } 49 & \text { Pakistan } & 16 \text { Jun } 52 \\ \text { India } & 28 \text { Dec } 49 & \text { Singapore } & \text { 7 Jun } 66 \\ \text { Iran } & 30 \text { Dec } 59 & \text { Sri Lanka } & \text { 14 Jul 49 }\end{array}$

Agreement for the Suppression of the Circulation of Obscene Publications

Paris, 4 May 1910, amended by Protocol, New York, 4 May 1949

Entry into force: 1 March 1950

$\begin{array}{llll}\text { State } & \text { Cons. } & \text { State } & \text { Cons. } \\ \text { Cambodia } & 30 \text { Mar 59 } & \text { Malaysia } & 31 \text { Aug } 57 \\ \text { China } & 4 \text { May } 49 & \text { Myanmar } & 13 \text { May } 49 \\ \text { India } & 28 \text { Dec } 49 & \text { Pakistan } & 4 \text { May } 51 \\ \text { Iran } & 30 \text { Dec 59 } & \text { Sri Lanka } & 14 \text { Jul } 49\end{array}$

Convention for the Suppression of the Traffic in Persons and of the Exploitation of the Prostitution of Others

New York, 21 March 1950

Entry into force: 25 July 1951

$\begin{array}{llllll}\begin{array}{l}\text { State } \\ \text { Afghanistan }\end{array} & \text { Sig. } & \text { Cons. } & \text { State } & \text { Sig. } & \text { Cons. } \\ \text { Bangladesh } & & \text { 21 May 85 } & \text { Laos } & & \text { 14 Apr 78 } \\ \text { India } & \text { 9 May 50 } & \text { 9 Jan 85 } & \text { Myanmar } & \text { 14 Mar 56 } & \\ \text { Iran } & \text { 16 Jul 53 } & \text { Pakistan } & \text { 21 Mar 50 } & \text { 11 Jul 52 } \\ \text { Japan } & & \text { 1 May 58 } & \text { Philippines } & \text { 20 Dec 50 } & \text { 19 Sep 52 } \\ \text { Korea (Rep.) } & & \text { 13 Feb 62 } & \text { Sri Lanka } & & \text { 26 Oct 66 } \\ & & & & \text { 15 Apr 58 }\end{array}$

Final Protocol to the Convention for the Suppression of the Traffic in Persons and of the Exploitation of the Prostitution of Others

New York, 21 March 1950

Entry into force: 25 July 1951

$\begin{array}{llllll}\text { State } & \text { Sig. } & \text { Cons. } & \text { State } & \text { Sig. } & \text { Cons. } \\ \text { India } & \text { 9 May 50 } & \text { 9 Jan 53 } & \text { Myanmar } & \text { 14 Mar 56 } & \\ \text { Iran } & \text { 16 Jul 53 } & & \text { Pakistan } & \text { 21 Mar 50 } & \\ \text { Japan } & & \text { 1 May 58 } & \text { Philippines } & \text { 20 Dec 50 } & \text { 19 Sep 52 } \\ \text { Korea (Rep.) } & & \text { 13 Feb 62 } & \text { Sri Lanka } & & \text { 7 Aug 58 }\end{array}$




\section{TELECOMMUNICATIONS}

\section{Constitution of the Asia-Pacific Telecommunity \\ ESCAP, Bangkok, 27 March 1976 \\ Entry into force: 25 February 1979}

\begin{tabular}{|c|c|c|c|c|c|}
\hline State & Sig. & Cons. & State & Sig. & Cons. \\
\hline Afghanistan & $12 \operatorname{Jan} 77$ & 17 May 77 & Malaysia & 23 Jun 77 & 23 Jun 77 \\
\hline Bangladesh & 1 Apr 76 & 22 Oct 76 & Maldives & & 17 Mar 80 \\
\hline Brunei & & 27 Mar 86 & Mongolia & & 14 Aug 91 \\
\hline China & 25 Oct 76 & 2 Jun 77 & Myanmar & 20 Oct 76 & $9 \operatorname{Dec} 76$ \\
\hline $\begin{array}{l}\text { Hong Kong } \\
\text { (by UK decl.) }\end{array}$ & 31 Aug 77 & 31 Aug 77 & $\begin{array}{l}\text { Nepal } \\
\text { Pakistan }\end{array}$ & $\begin{array}{l}15 \text { Sep } 76 \\
25 \text { Jan } 77\end{array}$ & $\begin{array}{l}12 \text { May } 77 \\
1 \text { Jul } 77\end{array}$ \\
\hline India & 28 Oct 76 & 26 Nov 76 & Papua New & & \\
\hline Indonesia & 29 Apr 85 & & Guinea & $29 \operatorname{Sep} 76$ & $17 \operatorname{Dec} 92$ \\
\hline Iran & 15 Sep 76 & 3 Mar 80 & Philippines & 28 Oct 76 & 17 Jun 77 \\
\hline Japan & $22 \operatorname{Mar} 77$ & 25 Nov 77 & Singapore & 23 Jun 77 & 6 Oct 77 \\
\hline Korea (DPR) & 22 Feb 94 & & Sri Lanka & & 3 Oct 79 \\
\hline Korea (Rep.) & 8 Jul 77 & 8 Jul 77 & Thailand & $15 \operatorname{Sep} 76$ & $26 \mathrm{Jan} 79$ \\
\hline Laos & & 20 Oct 89 & Vietnam & & 11 Sep 79 \\
\hline Macau (associa & nember) & 9 Feb 93 & & & \\
\hline
\end{tabular}

Amendments to Article 11, Paragraph 2(a), of the Constitution of the Asia-Pacific Telecommunity

Bangkok, 13 November 1981

Entry into force: 2 January 1985

\begin{tabular}{|c|c|c|c|}
\hline State & Cons. & State & Cons. \\
\hline Afghanistan & $22 \mathrm{Jul} 83$ & Myanmar & 27 Sep 84 \\
\hline Bangladesh & 9 Feb 88 & Nepal & $3 \mathrm{Dec} 84$ \\
\hline China & $26 \mathrm{Jul} 82$ & Pakistan & 24 Aug 84 \\
\hline India & $15 \mathrm{Jul} 83$ & Singapore & 22 Jul 82 \\
\hline Iran & 10 Apr 86 & Sri Lanka & 26 Mar 82 \\
\hline Korea (Rep.) & 2 Jul 82 & Thailand & 1 Nov 82 \\
\hline Malaysia & 7 Jan 86 & Vietnam & $28 \mathrm{Dec} 83$ \\
\hline Maldives & 28 May 82 & & \\
\hline
\end{tabular}

Amendments to articles 3(5) and 9(8) of the Constitution of the Asia-Pacific Telecommunity Colombo, 29 November 1991

Entry into force: -

$\begin{array}{llll}\text { State } & \text { Cons. } & \text { State } & \text { Cons. } \\ \text { Brunei } & 4 \text { Feb } 94 & \text { Korea (Rep.) } & 18 \text { Feb } 93 \\ \text { China } & 25 \text { May } 93 & \text { Maldives } & \text { 3 Feb } 93 \\ \text { Indonesia } & 26 \text { Sep } 94 & \text { Thailand } & 14 \text { Jan } 94\end{array}$

\section{Convention on the International Maritime Satellite Organization (INMARSAT)}

London, 3 September 1976, as amended

Entry into force: 16 July 1979

(Status as included in IMO Doc. J/6233, as at 31 December 1995) 


\begin{tabular}{|c|c|c|c|c|c|}
\hline State & Cons. & $\begin{array}{l}\text { Cons. } \\
\text { Amendm. } 1985\end{array}$ & State & Cons. & $\begin{array}{l}\text { Cons. } \\
\text { Amendm. } 198\end{array}$ \\
\hline Bangladesh & 17 Sep 93 & & Korea (Rep.) & $16 \operatorname{Sep} 85$ & \\
\hline Brunei & 4 Oct 94 & & Malaysia & 12 Jun 86 & \\
\hline China & 13 Jul 79 & 15 May 86 & Pakistan & 6 Feb 85 & \\
\hline India & 6 Jun 78 & & Philippines & 30 Mar 81 & 17 Aug 87 \\
\hline Indonesia & 9 Oct 86 & & Singapore & 29 Jun 79 & 6 Oct 88 \\
\hline Iran & 12 Oct 84 & & Sri Lanka & 15 Dec 81 & 10 Jun 86 \\
\hline Japan & 25 Nov 77 & & Thailand & 14 Dec 94 & \\
\hline \multicolumn{6}{|c|}{$\begin{array}{l}\text { Agreement establishing the Asia-Pacific Institute for Broad-casting Development } \\
\qquad \text { Kuala Lumpur, 12 August } 1977 \\
\text { Entry into force: } 6 \text { March } 1981\end{array}$} \\
\hline State & Sig. & Cons. & State & Sig. & Cons. \\
\hline Afghanistan & 23 Aug 78 & & Maldives & & 25 Jun 85 \\
\hline Bangladesh & 14 Sep 77 & 11 Aug 81 & Nepal & 15 May 80 & 11 Sep 80 \\
\hline Brunei & & 6 Dec 88 & Pakistan & 10 Apr 78 & 7 Jul 81 \\
\hline China & & $5 \mathrm{Feb} 88$ & Papua New & & \\
\hline India & 20 May 80 & $25 \mathrm{Feb} 86$ & Guinea & 9 Mar 78 & 1 May 80 \\
\hline Indonesia & 12 Aug 78 & 31 Aug 89 & Philippines & 12 Sep 77 & \\
\hline Iran & & 18 Nov 96 & Singapore & & 29 Jun 82 \\
\hline Korea (Rep.) & 11 Oct 78 & 6 Mar 81 & Sri Lanka & 15 Sep 78 & 7 Nov 88 \\
\hline Laos & & $12 \operatorname{Sep} 86$ & Thailand & 25 Apr 81 & \\
\hline Malaysia & 11 Oct 78 & 10 Nov 80 & Vietnam & 8 Sep 78 & 23 Feb 81 \\
\hline
\end{tabular}

\section{TREATIES}

Convention on the Law of Treaties Vienna, 23 May 1969

Entry into force: 27 January 1980

$\begin{array}{lcllll}\text { State } & \text { Sig. } & \text { Cons. } & \text { State } & \text { Sig. } & \text { Cons. } \\ \text { Afghanistan } & \text { 23 May 69 } & & \text { Mongolia } & & \text { 16 May 88 } \\ \text { Cambodia } & \text { 23 May 69 } & & \text { Nepal } & \text { 23 May 69 } & \\ \text { Iran } & \text { 23 May 69 } & & \text { Pakistan } & \text { 29 Apr 70 } & \\ \text { Japan } & & \text { 2 Jul 81 } & \text { Philippines } & \text { 23 May 69 } & \text { 15 Nov 72 } \\ \text { Kazkhstan } & & \text { 5 Jan 94 } & \text { Tajikistan } & & \text { 6 May 96 } \\ \text { Korea (Rep.) } & 27 \text { Nov 69 } & \text { 27 Apr 77 } & \text { Turkmenistan } & & \text { 4 Jan 96 } \\ \text { Malaysia } & & \text { 27 Jul 94 } & \text { Uzbekistan } & & \text { 12 Jul 95 }\end{array}$

Vienna Convention on the Law of Treaties Between States and International Organizations or Between International Organizations

Vienna, 21 March 1986

Entry into force: -

$\begin{array}{llllll}\text { State } & \text { Sig. } & \text { Cons. } & \text { State } & \text { Sig. } & \text { Cons. } \\ \text { Japan } & 24 \text { Apr } 87 & & \text { Korea (Rep.) } & \text { 29 Jun 87 } & \end{array}$




\section{WEAPONS}

Protocol for the Prohibition of the Use in War of Asphyxiating, Poisonous or Other Gases, and of Bacteriological Warfare

Geneva, 17 June 1925

Entry into force: 8 February 1928

(Status as included in A/46/604 and TIF)

\begin{tabular}{|c|c|c|c|c|c|}
\hline State & Sig. & Cons. & State & Sig. & Cons \\
\hline Afghanistan & & yes & Malaysia & & yes \\
\hline Bangladesh & & 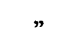 & Maldives & & " \\
\hline Bhutan & & ” & Mongolia & & ” \\
\hline Cambodia & & " & Nepal & & $"$ \\
\hline China & & $"$ & Pakistan & & " \\
\hline India & yes & ” & Papua New & & \\
\hline Indonesia & & ” & Guinea & & ” \\
\hline Iran & & ” & Philippines & & ” \\
\hline Japan & n & ” & Sri Lanka & & " \\
\hline Korea (DPR) & & " & Thailand & yes & ” \\
\hline Korea (Rep.) & • & $"$ & Vietnam & & $"$ \\
\hline
\end{tabular}

Treaty Banning Nuclear Weapon Tests in the Atmosphere, in Outer Space and Under Water

Moscow, 5 August 1963

Entry into force: 10 October 1963

(Status as included in A/46/604 and TIF)

\begin{tabular}{|c|c|c|c|c|c|}
\hline State & Sig. & Cons. & State & Sig. & Cons \\
\hline Afghanistan & yes & yes & Mongolia & yes & yes \\
\hline Bangladesh & & ” & Myanmar & ” & ” \\
\hline Bhutan & & $"$ & Nepal & $"$ & $"$ \\
\hline India & " & $"$ & Pakistan & 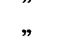 & $"$ \\
\hline Indonesia & $"$ & $"$ & Papua & & \\
\hline Iran & " & , & New G & & $\eta$ \\
\hline Japan & ” & ” & Philippines & n & " \\
\hline Korea (Rep.) & " & " & Singapore & & \\
\hline Laos & ” & $"$ & Sri Lanka & ” & $"$ \\
\hline Malaysia & $"$ & $"$ & Thailand & $"$ & $"$ \\
\hline
\end{tabular}

Treaty on the Non-Proliferation of Nuclear Weapons

London, Moscow, Washington, 1 July 1968

Entry into force: 5 March 1970

(Status as included in A/46/604 and TIF) 


\begin{tabular}{|c|c|c|c|c|c|}
\hline State & Sig. & Cons. & State & Sig. & Cons \\
\hline Afghanistan & yes & yes & Malaysia & yes & yes \\
\hline Bangladesh & & $\eta$ & Mongolia & " & 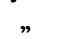 \\
\hline Brunei & & ” & Nepal & " & ” \\
\hline Cambodia & & $\eta$ & Papua & & \\
\hline Indonesia & $\eta$ & ” & New Gui & & " \\
\hline Iran & ” & ” & Philippines & " & " \\
\hline Japan & ” & $n$ & Sri Lanka & ” & ” \\
\hline Korea (DPR) & " & & Thailand & & $"$ \\
\hline Korea (Rep.) & " & \# & Vietnam & & 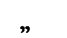 \\
\hline Laos & ” & \# & & & \\
\hline
\end{tabular}

Treaty on the Prohibition of the Emplacement of Nuclear Weapons and Other Weapons of Mass Destruction on the Sea-Bed and the Ocean Floor and in the Subsoil Thereof London, Moscow, Washington, 11 February 1971

Entry into force: 18 May 1972

(Status as included in A/46/604 and TIF)

\begin{tabular}{|c|c|c|c|c|}
\hline State & Sig. & Cons. & State & Cons. \\
\hline Afghanistan & yes & yes & Laos & yes \\
\hline Cambodia & $"$ & & Malaysia & $"$ \\
\hline China & & " & Mongolia & $n$ \\
\hline India & & n & Myanmar & n \\
\hline Iran & " & 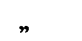 & Singapore & 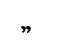 \\
\hline Japan & $”$ & $"$ & Vietnam & \\
\hline Korea (Rep.) & $n$ & 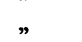 & & \\
\hline
\end{tabular}

Convention on the Prohibition of the Development, Production and Stockpiling of Bacteriological (Biological) and Toxin Weapons and on Their Destruction

London, Moscow, Washington, 10 April 1972

Entry into force: 26 March 1975

(Status as included in A/46/604 and TIF)

\begin{tabular}{|c|c|c|c|c|c|}
\hline State & Sig. & Cons. & State & Sig. & Cons \\
\hline Afghanistan & yes & yes & Malaysia & yes & \\
\hline Bangladesh & & $\eta$ & Mongolia & , & yes \\
\hline Brunei & & ” & Myanmar & n & \\
\hline Cambodia & ” & ” & Nepal & ” & \\
\hline China & & ” & Pakistan & n & n \\
\hline India & ” & n & Papua & & \\
\hline Indonesia & ” & & New Gu & & ” \\
\hline Iran & n & n & Philippines & ” & $n$ \\
\hline Japan & $"$ & $n$ & Singapore & 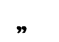 & $"$ \\
\hline Korea (DPR) & & ” & Sri Lanka & ” & n \\
\hline Korea (Rep.) & ” & n & Thailand & ” & ” \\
\hline Laos & n & n & Vietnam & & ” \\
\hline
\end{tabular}




\section{Convention on the Prohibition of Military or any other Hostile Use of Environmental Modification Techniques}

New York, 10 December 1976

Entry into force: 5 October 1978

\begin{tabular}{|c|c|c|c|c|c|}
\hline State & Sig. & Cons. & State & Sig. & Cons. \\
\hline Afghanistan & & 22 Oct 85 & Mongolia & 18 May 77 & 19 May 78 \\
\hline Bangladesh & & 3 Oct 79 & Pakistan & & $27 \mathrm{Feb} 86$ \\
\hline India & $15 \operatorname{Dec} 77$ & $15 \operatorname{Dec} 78$ & Papua & & \\
\hline Iran & 18 May 77 & & New Guinea & & 28 Oct 80 \\
\hline Japan & & 9 Jun 82 & Sri Lanka & 8 Jun 77 & 25 Apr 78 \\
\hline Korea (DPR) & & 8 Nov 84 & Uzbekistan & & 26 May 93 \\
\hline Korea (rep.) & & 2 Dec 86 & Vietnam & & 26 Aug 80 \\
\hline Laos & $13 \mathrm{Apr} 78$ & 5 Oct 78 & & & \\
\hline
\end{tabular}

Convention on Prohibitions or Restrictions on the Use of Certain Conventional Weapons which may be Deemed Excessively Injurious or to have Indiscriminate Effects, and Protocols

Geneva, 10 October 1980

Entry into force: 2 December 1983

$\begin{array}{llllll}\text { State } & \text { Sig. } & \text { Cons. } & \text { State } & \text { Sig. } & \text { Cons. } \\ \text { Afghanistan } & \text { 10 Apr 81 } & & \text { Mongolia } & \text { 10 Apr 81 } & \text { 8 Jun 82 } \\ \text { China } & \text { 14 Sep 81 } & \text { 7 Apr 82 } & \text { Pakistan } & \text { 26 Jan 82 } & \text { 1 Apr 85 } \\ \text { India } & \text { 15 May 81 } & \text { 1 Mar 84 } & \text { Philippines } & \text { 15 May 81 } & \text { 15 Jul 96 } \\ \text { Japan } & \text { 22 Sep 81 } & \text { 9 Jun 82 } & \text { Vietnam } & \text { 10 Apr 81 } & \\ \text { Laos } & \text { 2 Nov 82 } & \text { 3 Jan 83 } & & & \end{array}$

Convention on the Prohibition of the Development, Production, Stockpiling and Use of Chemical Weapons and on Their Destruction

Paris, 13 January 1993

Entry into force: 29 April 1997

$\begin{array}{llllll}\text { State } & \text { Sig. } & \text { Cons. } & \text { State } & \text { Sig. } & \text { Cons. } \\ \text { Afghanistan } & \text { 14 Jan 93 } & & \text { Mongolia } & \text { 14 Jan 93 } & \text { 17 Jan 95 } \\ \text { Bangladesh } & \text { 14 Jan 93 } & & \text { Myanmar } & \text { 14 Jan 93 } & \\ \begin{array}{l}\text { Brunei } \\ \text { Cambodia }\end{array} & \text { 13 Jan 93 } & & \text { Nepal } & \text { 19 Jan 93 } & \\ \text { China } & \text { 15 Jan 93 } & & \text { Pakistan } & \text { 13 Jan 93 } & \\ \text { India } & \text { 14 Jan 93 } & \text { 3 Sep 96 } & \begin{array}{l}\text { Papua New } \\ \text { Guinea }\end{array} & \text { 14 Jan 93 } & \text { 17 Apr 96 } \\ \text { Indonesia } & \text { 13 Jan 93 } & & \text { Philippines } & \text { 13 Jan 93 } & \text { 11 Dec } 96 \\ \text { Iran } & \text { 13 Jan 93 } & & \text { Singapore } & \text { 14 Jan 93 } & \\ \text { Japan } & \text { 13 Jan 93 } & \text { 15 Sep 95 } & \text { Sri Lanka } & \text { 14 Jan 93 } & \text { 19 Aug 94 } \\ \text { Kazakhstan } & \text { 14 Jan 93 } & & \text { Tajikistan } & \text { 14 Jan 93 } & \text { 11 Jan 95 } \\ \text { Korea (Rep.) } & \text { 14 Jan 93 } & & \text { Thailand } & \text { 14 Jan 93 } & \\ \text { Kyrgyzstan } & \text { 22 Feb 93 } & & \text { Turkmenistan } & \text { 12 Oct 93 } & \text { 29 Sep 94 } \\ \text { Laos } & \text { 13 May 93 } & & \text { Uzbekistan } & \text { 24 Nov 95 } & \text { 23 Jul 96 } \\ \text { Malaysia } & \text { 13 Jan 93 } & & \text { Vietnam } & \text { 13 Jan 93 } & \\ \text { Maldives } & \text { 4 Oct 93 } & \text { 31 May 94 } & & & \end{array}$

